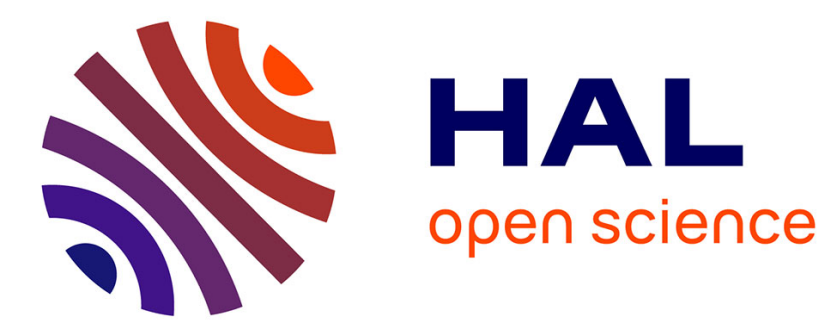

\title{
Dynamic crushing of wood-based sandwich composite tubes
}

Romain Guélou, Florent Eyma, Arthur Cantarel, Samuel Rivallant, Bruno

Castanié

\section{- To cite this version:}

Romain Guélou, Florent Eyma, Arthur Cantarel, Samuel Rivallant, Bruno Castanié. Dynamic crushing of wood-based sandwich composite tubes. Mechanics of Advanced Materials and Structures, 2021, pp.1-21. 10.1080/15376494.2021.1991533 . hal-03407710

\section{HAL Id: hal-03407710 https://hal.science/hal-03407710}

Submitted on 28 Oct 2021

HAL is a multi-disciplinary open access archive for the deposit and dissemination of scientific research documents, whether they are published or not. The documents may come from teaching and research institutions in France or abroad, or from public or private research centers.
L'archive ouverte pluridisciplinaire HAL, est destinée au dépôt et à la diffusion de documents scientifiques de niveau recherche, publiés ou non, émanant des établissements d'enseignement et de recherche français ou étrangers, des laboratoires publics ou privés. 


\title{
Dynamic crushing of wood based sandwich composite tubes
}

\author{
R. Guéloua, F. Eymaa, A. Cantarela, S. Rivallanta, B. Castaniéa, ${ }^{\star}$ \\ alnstitut Clément Ader (ICA), ISAE, CNRS UMR 5312-INSA-Mines Albi-UPS, Toulouse, France \\ *Corresponding author: bruno.castanie@insa-toulouse.fr
}

(

Keywords: Wood veneers, Poplar, Composites, Sandwich, Crushing, Energy absorption, Tube, Dynamic

Abstract: The paper presents the results of dynamic crushing of sandwich tubes that had skins made of carbon or glass fibres - with epoxy resin - and an I214 poplar ply core. By increasing the number of poplar plies from two to six, the absorbed energy is doubled, showing the significant contribution of the wood. The Specific Energy Absorption of sandwiches with carbon fibre skins oscillated between 49.4 and $60 \mathrm{~J} / \mathrm{g}$ while that with glass fibre skins varied from 35.4 to $43.3 \mathrm{~J} / \mathrm{g}$.

\section{Introduction}

Wood is a material that is respectful of the environment because it is renewable and requires little embodied energy (energy corresponding to the transformation of the raw product into the finished product) due to its ability to store carbon [1,2]. Wood is considered to be a credible substitute material for meeting sustainable development targets, particularly in the field of transport [3]. It is a material that has been used for many years in both civil engineering and aeronautics, where planes were made of wood until World War II and showed remarkable levels of performance [4]. Several French companies are showing renewed interest by either pursuing wood construction (Robin Aircraft [5]) with the DR401 (2700 units since 1972) or introducing it into their most recent structures ([6,7]). Studies have also shown that this material is particularly interesting for automobiles $[8,9]$. This renewal of interest is also shared by the academic world and recent studies demonstrate the interest of wood alone or in combination with natural fibres or modern materials such as glass, Kevlar, carbon or even aluminium, in particular in sandwich form [10-16]. An increasing number of recent academic studies have also shown 
that wood has very good mechanical characteristics at low speed-low energy impact [17-23] and in compression after impact, with behaviour that is sometimes surprising compared to that of composites. The knockdown factor can reach $70 \%$ for classical carbon Nomex sandwich and is less than $10 \%$ in certain configurations with plywood cores [24-26]. Historically, wood has also been identified as a material with good dynamic and crash absorption characteristics and has been used for a very long time, for example, in the transport of radioactive materials [27-28]. In previous papers, the authors looked into the crash behaviour of tubes laminated with plies in poplar alone I214 [29] and were able to show that this wood, one of the cheapest and lightest, had good SEA up to $30 \mathrm{~J} / \mathrm{kg}$ for a material 40 times less expensive than CFRP, and renewable. As with composite tubes, exterior polar plies oriented at $90^{\circ}$ and creating a "hoop effect" increased resistance to the crushing force, thus improving the SEA. It is therefore clear that sandwich tubes with a core in I214 poplar plies and the interior and exterior skins of the tube in carbon and fibreglass fabrics should be the next step. These configurations have been tested under quasi-static loads in [30]. It was shown that better energy absorption was obtained with all the poplar veneers at $0^{\circ}$ because the "hoop effect" ensured by the outer and inner composite layers was sufficient. The average SEA of tubes with carbon skins was $61.2 \mathrm{~J} / \mathrm{g}$ and remains quite constant, for an SEA gain of around 47\% with respect to the sum of the two materials crushed independently. An average SEA of $32.5 \mathrm{~J} / \mathrm{g}$ was obtained for tubes with glass skins. Coupling 1214 poplar veneers with glass fibres allowed, in particular, a gain of $20 \%$ on absorbed energy and $22 \%$ on the SEA.

This paper is the continuation of [30] and presents the dynamic crushing of sandwich tubes with composite skins in carbon or glass fibres and a core in 1214 poplar veneers. The objective is to understand the behaviour of these structures from the point of view of dynamics.

50

2. Materials, test specimens and setup

\subsection{Materials and manufacturing}


53 The sandwich tubes were manufactured using a metal mandrel, on which the two inner composite

54 layers (carbon or glass fabrics) were stacked first. It was presented in [30] and is briefly recalled here. The $1 \mathrm{~mm}$ thick 1214 poplar veneers, supplied by the Garnica company, were then wound up. A heatshrinkable tape was wound around them to provide pressure during crosslinking. After this first curing cycle, the 2 outer composite plies (carbon or glass fabrics) were finally stacked and a second curing cycle was performed with a wound heat-shrink band.

59 The monolithic carbon or glass tubes were manufactured in the same way: four composite plies were stacked over the metal mandrel and a heat-shrinkable strip was wound around them. The curing cycles were as follows:

- For carbon, $30 \mathrm{~min}$ at $90^{\circ} \mathrm{C}$ then $2 \mathrm{~h} 20 \mathrm{~min}$ at $120^{\circ} \mathrm{C}$, - For glass, 30 min at $90^{\circ} \mathrm{C}$ then 1 hour at $120^{\circ} \mathrm{C}$.

64 The prepregs used were supplied by Hexcel: the carbon plies were made with the prepreg 65 M79/42\%/200T2/ CHR-3K and the glass plies were in prepreg M9.6GF/42\%/200T2/G, inducing theoretical fibre volume fractions of $44 \%$ and $39 \%$ respectively. These two prepregs were $2-2$ twills having an areal weight of $345 \mathrm{~g} / \mathrm{m}^{2}$ and were oriented at [0/90] to obtain a hoop effect.

The wood glue used to pre-glue the veneers before they were rolled up was Kleiberit PUR 510 FIBERBOND glue, a one-component polyurethane-based glue that hardens by reaction with humidity, with a basis weight of $250 \mathrm{~g} / \mathrm{m}^{2}$. When the 1214 poplar veneers had been stacked around the mandrel, the bonding was carried out with a relative humidity of between 8.8 and $9.8 \%$. The density of the 1214 veneers was $0.368 \mathrm{~g} / \mathrm{cm}^{3}$.

73 The inner diameter of the tubes was $50 \mathrm{~mm}$ and their final length was $120 \mathrm{~mm}$. A $45^{\circ}$ chamfer was

74 made around the entire thickness of the tubes (Fig. 1) in order to lower the peak load and control the 75 side of failure initiation. 


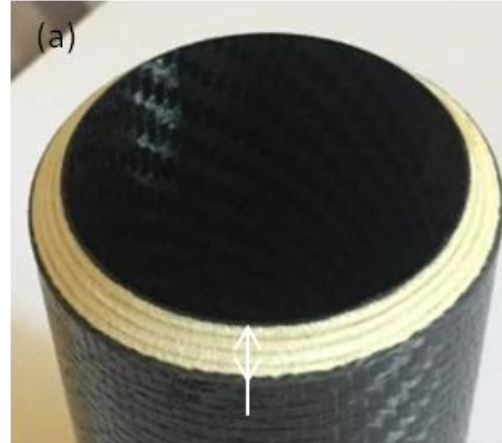

$5.2 \mathrm{~mm}$ (b)

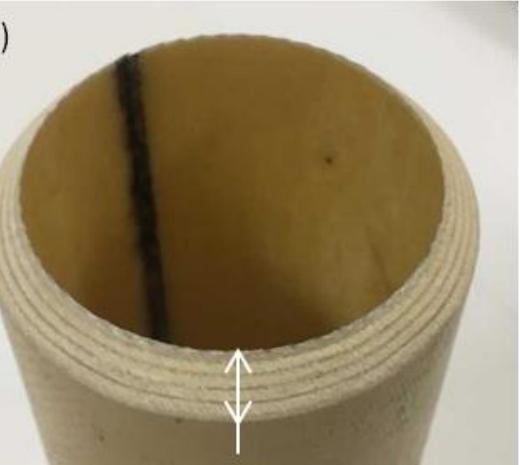

$4.8 \mathrm{~mm}$

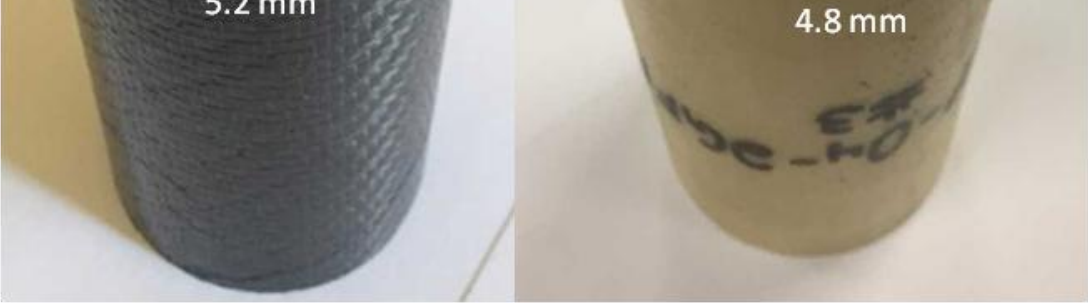

Fig. 1: Pristine sandwich tubes, (a) [2CFRP-[04]-2CFRP]-\#3, (b) [2CFRP-[04]-2CFRP]-\#3

The effect of wood was studied by varying the number of I214 plies from two to six while keeping a constant number of interior and exterior composite plies (carbon or glass). A sandwich tube had two interior composite plies and two exterior plies that thus constituted the skins. The composite tubes alone, intended for the evaluation of the coupling effects, then had four 4 plies in total. The sandwich tubes were defined by the following notation: [2GFRP- [On] -2GFRP] describing two glass plies on the inside and two plies on the outside, and $\mathrm{n}$ poplar plies oriented at $0^{\circ}\left(0^{\circ}\right.$ being the longitudinal axis of the tube). The composite tubes were then defined by the notation [GFRP] or [CFRP] depending on the nature of the fibres. They always had four plies in total.

\begin{tabular}{|c|c|}
\cline { 2 - 2 } \multicolumn{1}{c|}{} & Dynamic \\
\hline$\left[2 \mathrm{CFRP}-\left[\mathrm{O}_{6}\right]-2 \mathrm{CFRP}\right]$ & 3 \\
\hline$\left[2 \mathrm{CFRP}-\left[\mathrm{0}_{5}\right]-2 \mathrm{CFRP}\right]$ & 3 \\
\hline$\left[2 \mathrm{CFRP}-\left[\mathrm{O}_{4}\right]-2 \mathrm{CFRP}\right]$ & 3 \\
\hline$\left[2 \mathrm{CFRP}-\left[\mathrm{O}_{3}\right]-2 \mathrm{CFRP}\right]$ & 3 \\
\hline$\left[2 \mathrm{CFRP}-\left[\mathrm{O}_{2}\right]-2 \mathrm{CFRP}\right]$ & 3 \\
\hline$[$ CFRP] & 3 \\
\hline$\left[90 / 0_{4} / 90\right]$ (already crushed in $\left.[29]\right)$ & 3 \\
\hline
\end{tabular}

\begin{tabular}{|c|c|}
\hline & Dynamic \\
\hline [2GFRP-[06]-2GFRP] & 3 \\
\hline [2GFRP-[05]-2GFRP] & 3 \\
\hline [2GFRP-[04]-2GFRP] & 3 \\
\hline [2GFRP-[03]-2GFRP] & 3 \\
\hline [2GFRP-[0 2 ]-2GFRP] & 3 \\
\hline [GFRP] & 3 \\
\hline
\end{tabular}


87 The poplar veneers were characterized mechanically in [30] by carrying out six tensile tests on a

88 specimen of two 1214 plies glued together in the transverse and longitudinal directions (same wood glue 89 and same areal density).

\subsection{Dynamic setup}

91 As in [29], the dynamic tests were performed using a drop weight tower (Fig. 2). The initial crushing 92 speeds were between 8.4 and $8.8 \mathrm{~m} / \mathrm{s}$. The device was equipped with a ballast mass (81 or $114 \mathrm{~kg}$ 93 depending on the number of poplar plies). The mass of ballast was sufficient to provide more energy 94 than that absorbed by the tube, so as to obtain an almost constant crushing speed. The excess energy was collected by a stop system that transferred this excess to honeycombs located below the lower plate. The stops allowed approximately $85-90 \mathrm{~mm}$ to be crushed and enabled observation of the tubes

97 after crushing. A $100 \mathrm{kN}$ force sensor was located between the (upper) crushing plate and the masses 98 so that the force during the crushing could be acquired at a frequency of $1 \mathrm{MHz}$. A method of double 99 integration from the effort and the initial speed gave the displacement. The movement was also verified by means of images from high speed cameras that were synchronized with the force sensor. 

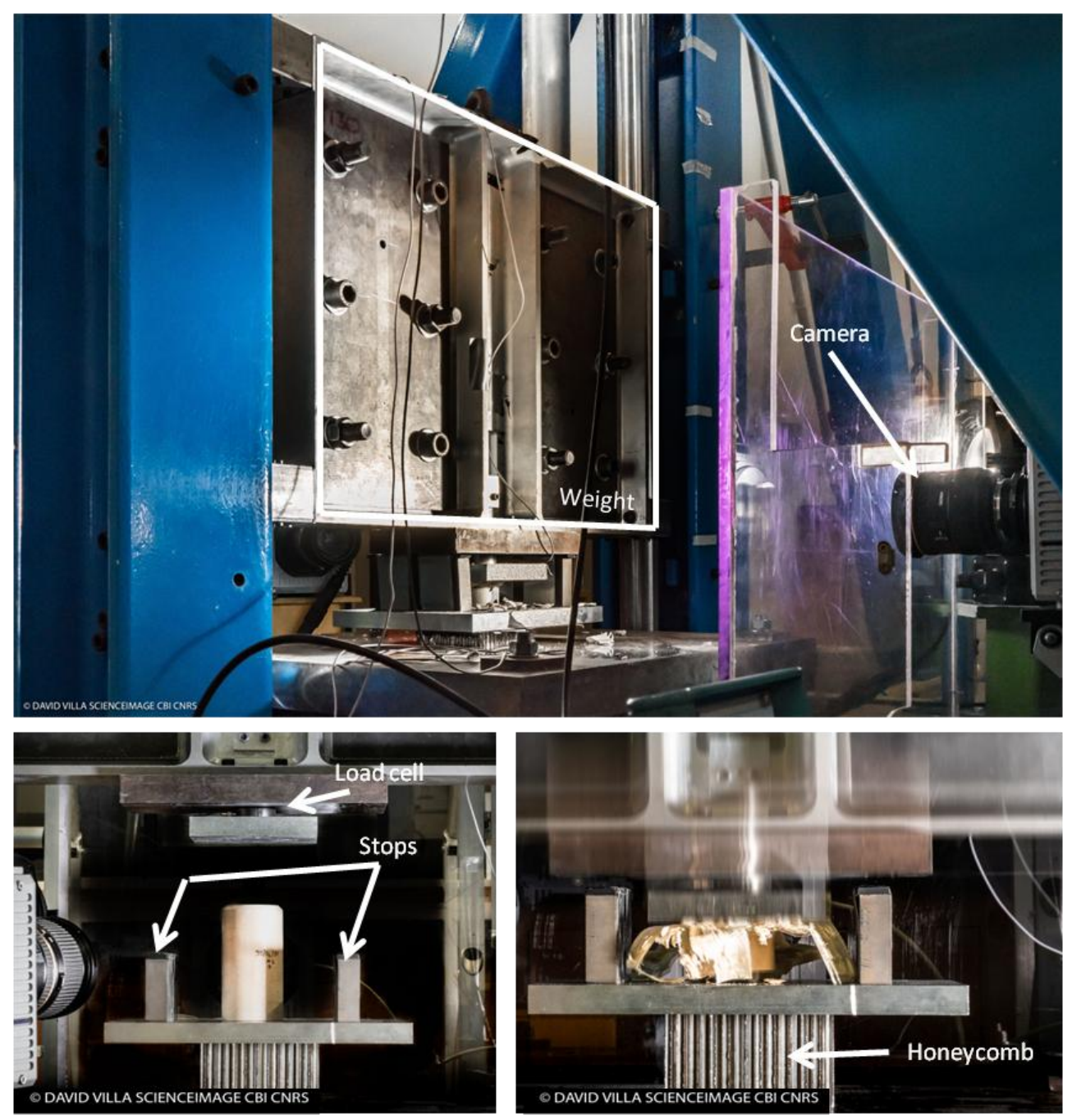

Fig. 2: Drop tower test device for dynamic crushing 
103 From the force-displacement curve obtained during the crush, several quantities and performance

104 criteria were extracted. The peak effort is noted $F_{\max }$. The average effort in the plateau is called $F_{\text {plateau. }}$

105 The CFE (Crush Force Efficiency) is the ratio between the average effort and the maximum effort

$106\left(\mathrm{~F}_{\text {plateau }} / \mathrm{F}_{\max }\right)$.

107 In general, when designing a shock absorber, a CFE very close to 1 is desirable, to limit the forces in

108 the rest of the structure during a crash. The energy absorbed here was calculated only on the first 80

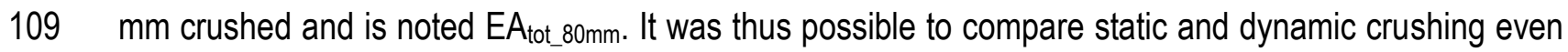

110 though the dynamic crushing lengths varied somewhat. Finally the SEA was also defined on the first 80

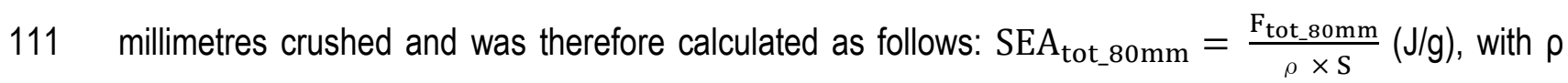

112 the average density of the tube (prepreg + glue + veneers) and $S$ the section.

113

114 3. Results and discussion

$115 \quad 3.1$ Sandwich tubes with carbon skins

116 The average crushing speed obtained from the falling weight tests was $8.8 \mathrm{~m} / \mathrm{s}$. The dynamic crushing 117 curves are shown in Fig. 3. 

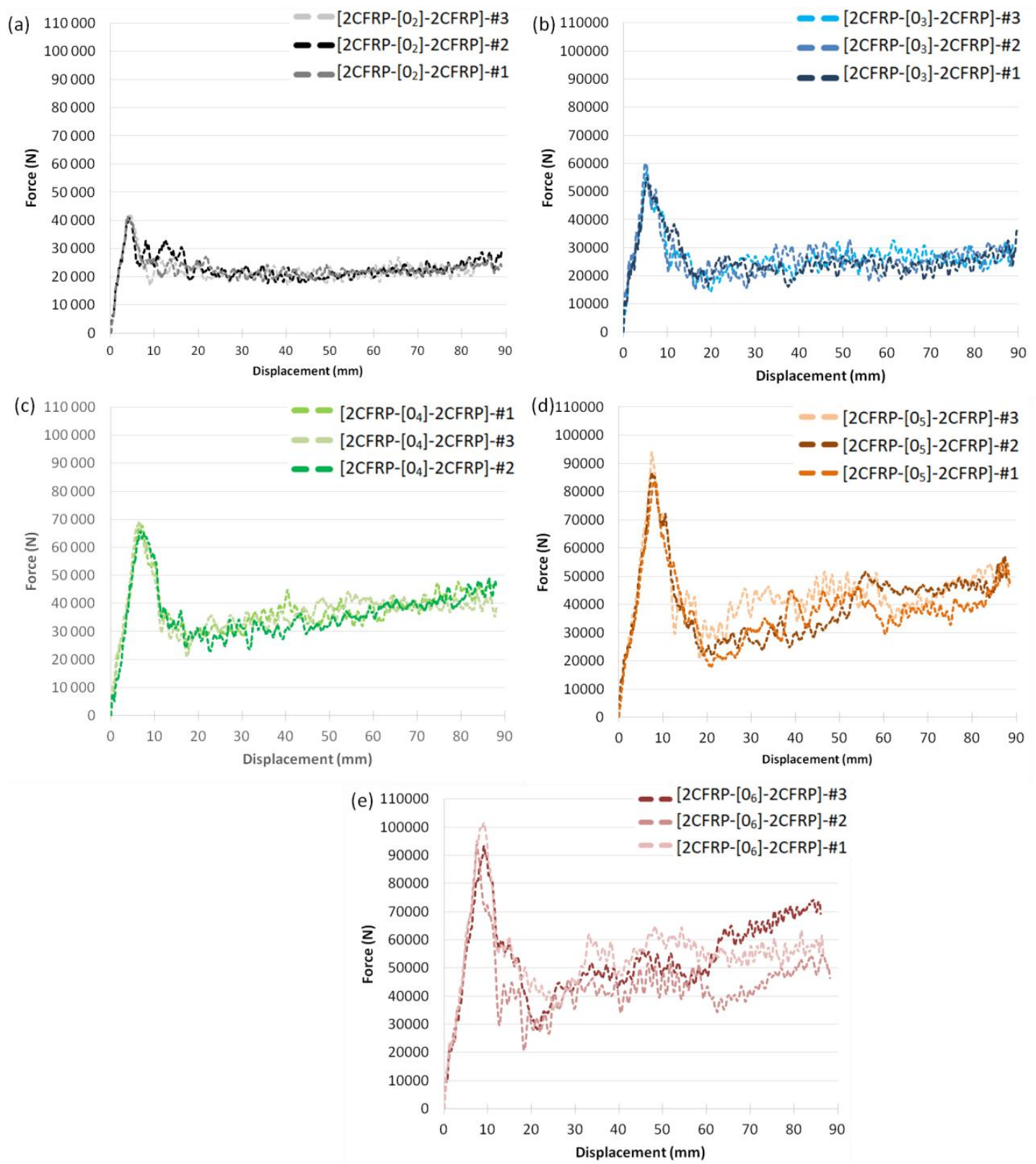

Fig. 3: Dynamic force-displacement curves of tubes (a) [2CFRP-[02]-2CFRP] (b) [2CFRP-[03]-2CFRP] (c) [2CFRP-[04]2CFRP] (d) [2CFRP-[05]-2CFRP] (e) [2CFRP-[06]-2CFRP]

121 The typical phases are visible: initiation, transition and plateau. For tubes with four, five or six I214 plies,

122 the plateau rises as the crushing advances. As the internal compaction of the debris occurs over the 123 same internal diameter, the more the number of 1214 plies increases, the more the compaction 124 participates in crushing (Fig. 6). The dynamic performances are presented in Tab. 2.

\begin{tabular}{|c|c|c|c|c|c|c|c|c|}
\hline & $\begin{array}{c}\text { Mass } \\
\mathrm{g}\end{array}$ & $\begin{array}{c}\text { Thickness } \\
\mathrm{mm}\end{array}$ & $\begin{array}{c}\mathbf{F}_{\max } \\
\mathbf{N}\end{array}$ & $\begin{array}{c}\text { Lplateau } \\
\mathrm{mm}\end{array}$ & $\begin{array}{c}F_{\text {plateau }} \\
\mathbf{N} \\
\end{array}$ & CFE & $\begin{array}{c}\text { EAtot_80mm } \\
\mathrm{J}\end{array}$ & $\begin{array}{c}\text { SEAtot_80mm } \\
\mathrm{J} / \mathrm{g}\end{array}$ \\
\hline$\left[2 \mathrm{CFRP}-\left[\mathrm{O}_{2}\right]-2 \mathrm{CFRF}\right.$ & 49.0 & 2.93 & 41389 & 81.4 & 20440 & 0.49 & 1718 & 54.3 \\
\hline [2CFRP-[0ㄱㄱ-2CFRP] - \#2 & 49.2 & 2.98 & 40825 & 82.6 & 22723 & 0.56 & 1807 & 54.4 \\
\hline$\left[2 \mathrm{CFRP}-\left[\mathrm{O}_{2}\right]-2 \mathrm{CFRP}\right]-\# 3$ & 49.1 & 2.92 & 42067 & 80.4 & 21782 & 0.52 & 1777 & 53.6 \\
\hline
\end{tabular}




\begin{tabular}{|c|c|c|c|c|c|c|c|c|}
\hline $\begin{array}{c}\text { Average } \\
\text { Standard deviation }\end{array}$ & $\begin{array}{c}49.1 \\
0.1 \\
\end{array}$ & $\begin{array}{l}2.94 \\
0.03\end{array}$ & $\begin{array}{c}41427 \\
622 \\
\end{array}$ & $\begin{array}{c}81.5 \\
1.1 \\
\end{array}$ & $\begin{array}{c}21649 \\
1147 \\
\end{array}$ & $\begin{array}{l}0.52 \\
0.03\end{array}$ & $\begin{array}{c}1767 \\
45 \\
\end{array}$ & $\begin{array}{l}54.1 \\
0.5 \\
\end{array}$ \\
\hline [2CFRP-[0 $\left.\left.{ }_{3}\right]-2 \mathrm{CFRP}\right]-\# 1$ & 61.8 & 4.34 & 54968 & 74.3 & 23739 & 0.43 & 2020 & 48.1 \\
\hline [2CFRP-[0 $\left.\left.{ }_{3}\right]-2 \mathrm{CFRP}\right]-\# 2$ & 61.8 & 4.35 & 60158 & 78.6 & 24871 & 0.41 & 2079 & 49.4 \\
\hline [2CFRP-[03]-2CFRP] - \#3 & 61.1 & 4.27 & 57269 & 78.4 & 25153 & 0.44 & 2110 & 50.8 \\
\hline Average & 61.6 & 4.32 & 57465 & 77.1 & 24588 & 0.43 & 2070 & 49.4 \\
\hline Standard deviation & 0.4 & 0.04 & 2601 & 2.4 & 749 & 0.01 & 46 & 1.3 \\
\hline [2CFRP-[04]-2CFRP] - \#1 & 75.7 & 5.20 & 68481 & 75.7 & 36682 & 0.54 & 2948 & 57.1 \\
\hline [2CFRP-[04]-2CFRP] - \#2 & 75.1 & 5.23 & 65819 & 76.3 & 35040 & 0.53 & 2812 & 54.8 \\
\hline [2CFRP-[04]-2CFRP] - \#3 & 75.2 & 5.19 & 69228 & 77.2 & 36140 & 0.52 & 2983 & 58.1 \\
\hline Average & 75.3 & 5.21 & 67843 & 76.4 & 35954 & 0.53 & 2915 & 56.7 \\
\hline Standard deviation & 0.3 & 0.02 & 1792 & 0.7 & 837 & 0.01 & 90 & 1.7 \\
\hline$\left[2 \mathrm{CFRP}-\left[0_{5}\right]-2 \mathrm{CFRP}\right]-\# 1$ & 91.8 & 6.37 & 93836 & 75.5 & 42392 & 0.45 & 3457 & 54.8 \\
\hline [2CFRP-[05]-2CFRP] - \#2 & 90.9 & 6.50 & 86722 & 74.6 & 37819 & 0.44 & 3132 & 50.1 \\
\hline [2CFRP-[05]-2CFRP] - \#3 & 88.9 & 6.44 & 83816 & 73.4 & 36083 & 0.43 & 2996 & 49.0 \\
\hline Average & 90.5 & 6.44 & 88125 & 74.5 & 38765 & 0.44 & 3195 & 51.3 \\
\hline Standard deviation & 1.5 & 0.07 & 5155 & 1.1 & 3259 & 0.01 & 237 & 3.1 \\
\hline [2CFRP-[06]-2CFRP] - \#1 & 102.0 & 7.51 & 101383 & 74.3 & 53462 & 0.53 & 4342 & 61.5 \\
\hline [2CFRP-[06]-2CFRP] - \#2 & 101.9 & 7.50 & 100587 & 71.8 & 50729 & 0.50 & 4178 & 59.3 \\
\hline [2CFRP-[06]-2CFRP] - \#3 & 102.3 & 7.65 & 93427 & 73.6 & 53184 & 0.57 & 4185 & 59.2 \\
\hline Average & 102.1 & 7.52 & 98466 & 73.2 & 52459 & 0.53 & 4235 & 60.0 \\
\hline Standard deviation & 0.2 & 0.03 & 4382 & 1.3 & 1504 & 0.03 & 93 & 1.3 \\
\hline
\end{tabular}

126 The failure mode of this configuration is initiated by the flattening of the chamfer in contact with the

127 crushing plate. The outer and inner skins then come into contact with the platter and are then forced to

128 splay inwards and outwards. The deformation imposed on the fibres oriented at $90^{\circ}$ causes them to 129 break and allows the tube to dissociate into bundles. As the crushing continues, the bundles and 130 splaying of the inner and outer skins create petals (Fig. 4). 

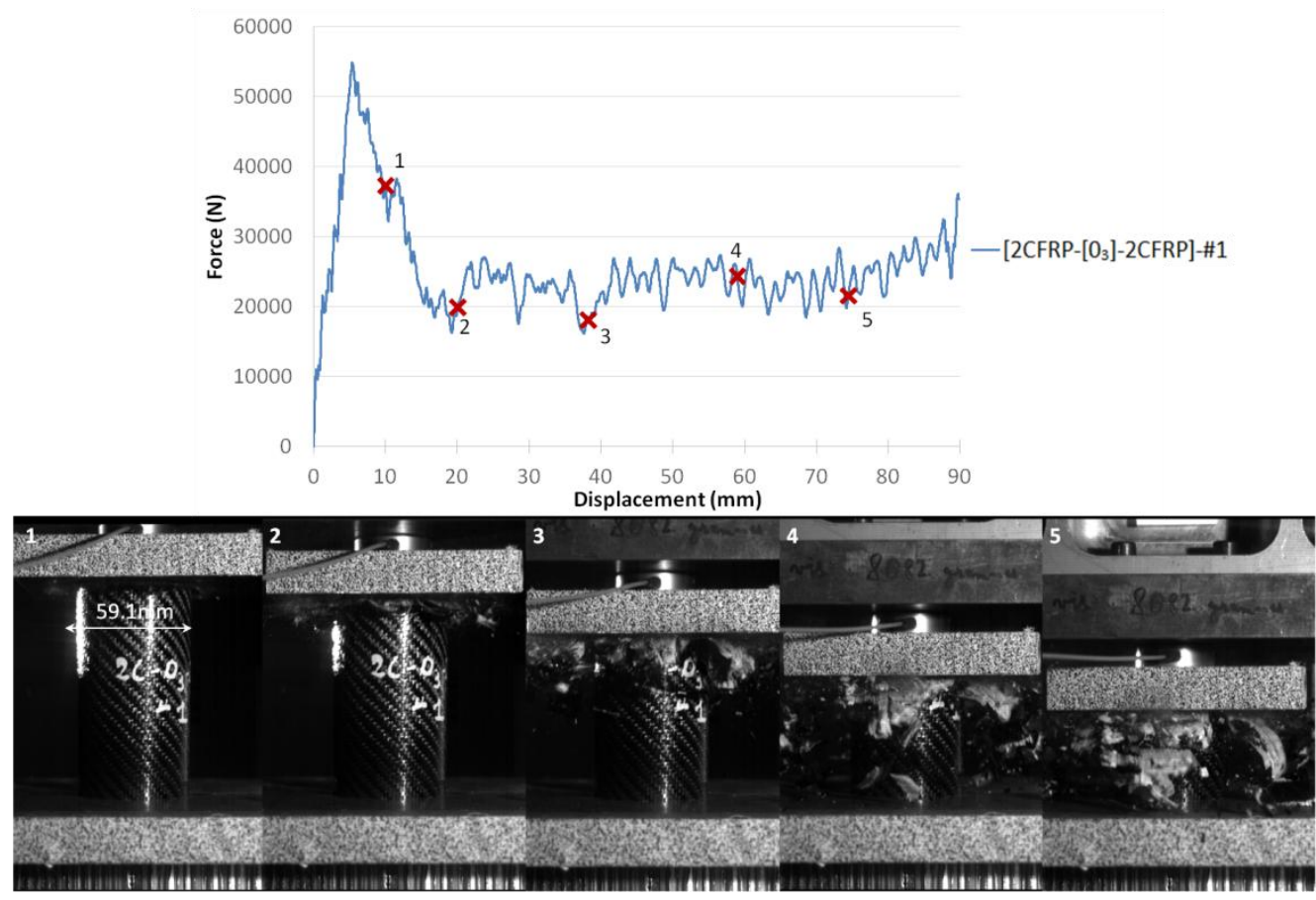

Fig. 4: Dynamic failure of tube [2CFRP-[0 $\left.\left.0_{3}\right]-2 \mathrm{CFRP}\right]-\# 1$ and association of pictures and points on the force displacement curve.

134 Post-crash analysis of the tubes shows fairly significant debris compaction within the tube (Fig. 5).

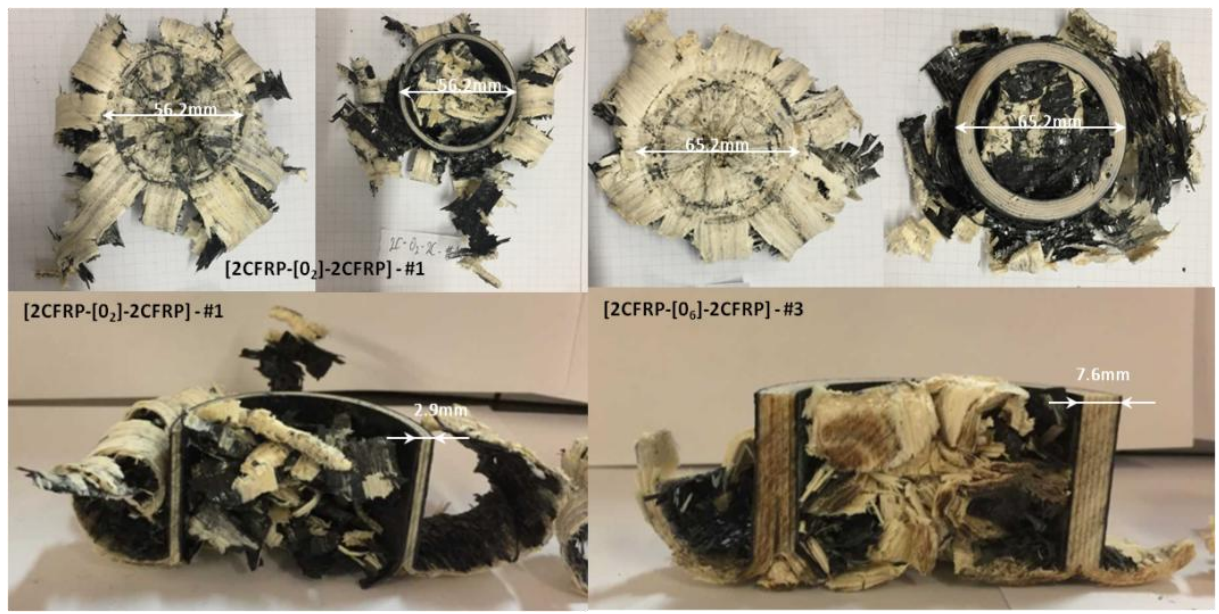

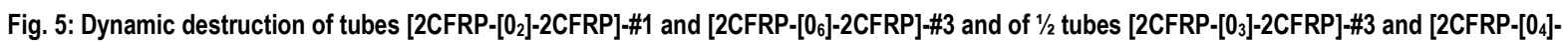
2CFRP]-\#1

138 The tubes have a generally similar failure mode but it is difficult to establish a link between the performance drops of configurations with different numbers of 1214 plies and the differences in failure modes: the same configuration can present different failure patterns (Fig. 6), a common item for issue in crash testing. 


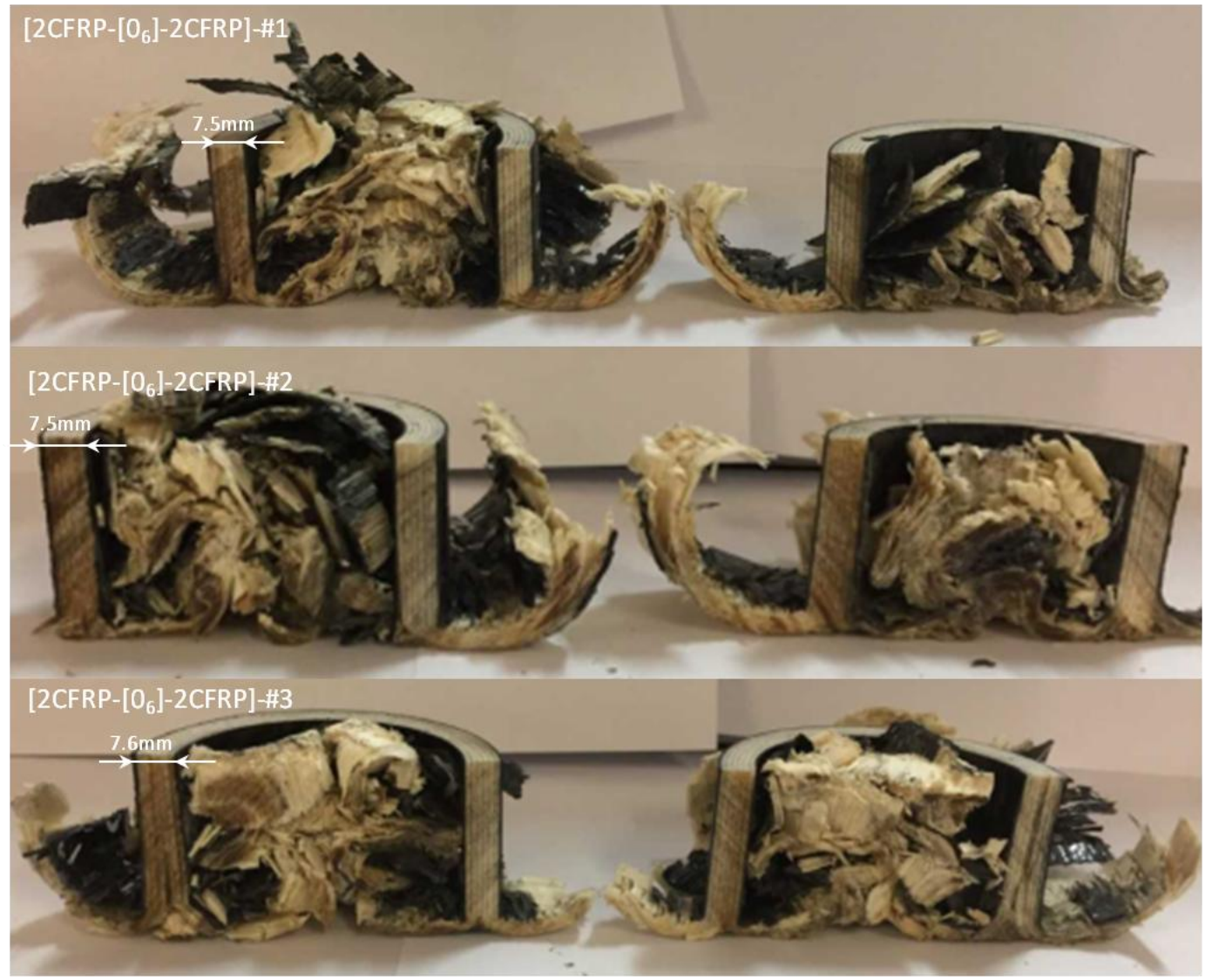

Fig. 6: Post-crush patterns of half sandwich tubes [2CFRP-[06]-2CFRP].

144 Here, for the [2CFRP-[06]-2CFRP] configuration, which shows good repeatability (Tab. 2) between these

145 tubes, the failure mode is generally similar but there are differences, e.g. different central cracking

146 position. Moreover, on the same tube, it can be seen that the failure front changes between the two half-

147 tubes: [2CFRP- [06] -2CFRP] \# 2, for example, exhibits one wall with bending over its entire 'thickness

148 while the other wall is divided into two inner and outer parts an inner and an outer part.

149 Absorbed energy and SEA are plotted versus the number of I214 folds in Fig. 7 (a). As splaying and

150 internal debris compaction constitute the overall ruin mechanism of each ply configuration, the peak

151 load and mean crush force at the plateau are plotted as a function of the section of the tubes in Fig. 7.

152 (b). 

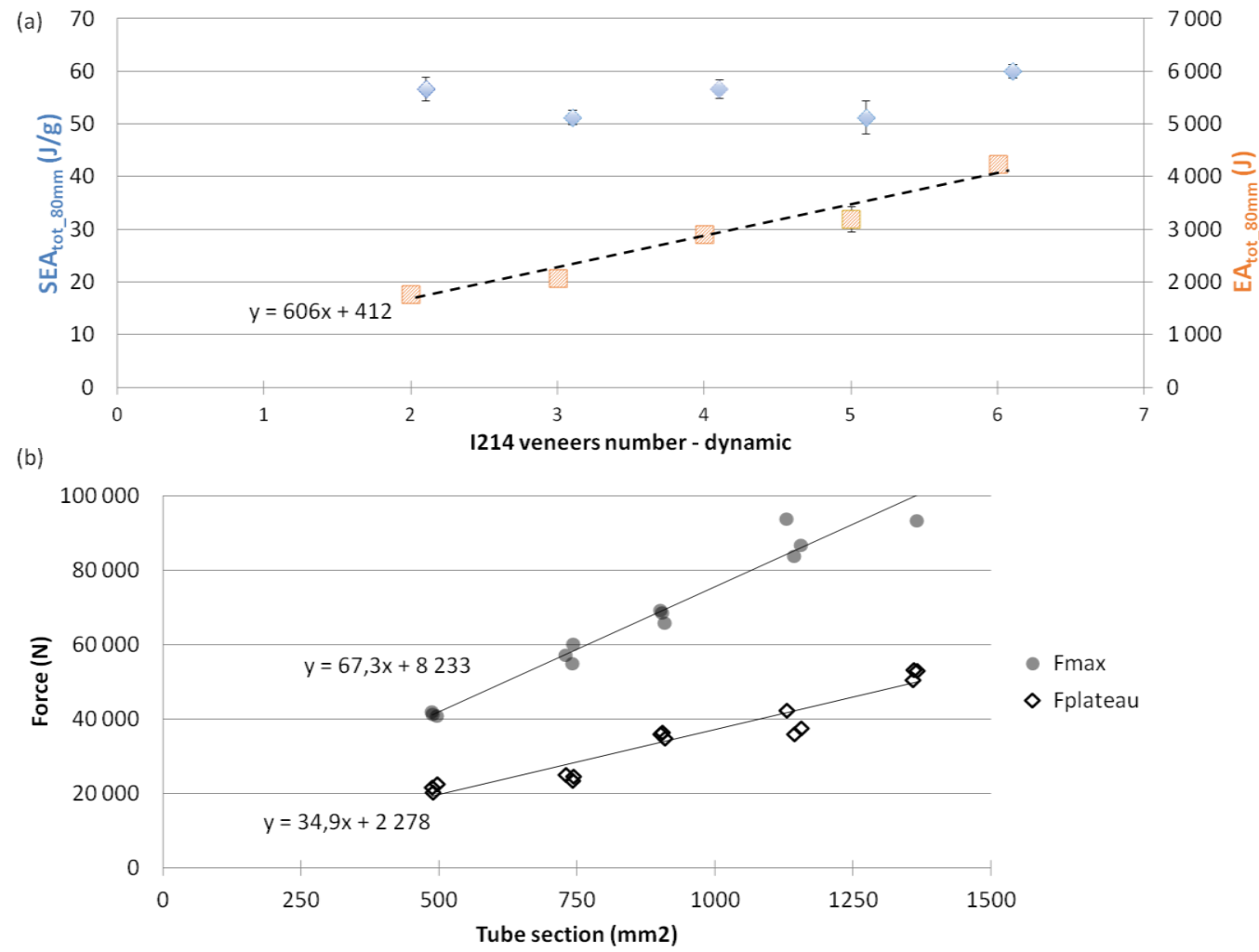

Fig. 7: (a) Evolution of EAtot_80mm and SEAtot_80mm versus the number of 1214 layers. (b) Maximum and plateau force versus tube sections for tubes with carbon skins.

The energy absorbed increases linearly with the number of 1214 folds, as expressed by the equation $E A_{\text {tot_80mm }}=606 \times$ number of layers $s_{I 214}+412$, with $606 \mathrm{~J}$ which would represent the contribution of a single 1214 poplar layer and $412 \mathrm{~J}$ the contribution of carbon skins. On average, the SEA oscillates between $48.1 \mathrm{~J} / \mathrm{g}$ for the lowest value ([2CFRP-[0 $\left.\left.\left.{ }_{3}\right]-2 \mathrm{CFRP}\right]\right)$ and $61.5 \mathrm{~J} / \mathrm{g}\left(\left[2 \mathrm{CFRP}-\left[0_{6}\right]-\right.\right.$ 2CFRP]).

The peak load and the mean crushing force increases linearly with the section. The load peaks are higher than the average forces, the difference depending on the section of the tubes OK? This is due to a more efficient failure mechanism during the loading phase than during the plateau phase. The equation of these two quantities confirms that the carbon fibre skins and the 1214 plies work more efficiently in the loading phase than in the plateau phase: $67.3 \mathrm{MPa}$ for the 1214 layers and $8233 \mathrm{~N}$ for the carbon skins versus $34.9 \mathrm{MPa}$ and $2278 \mathrm{~N}$ respectively. The average crush stress of an 1214 ply corresponds to overall failure mechanisms such as splaying and internal debris compaction and is 34.9 $\mathrm{MPa}$. 
171 The average crushing speed obtained from the falling weight tests was $8.4 \mathrm{~m} / \mathrm{s}$. The dynamic crushing 172 curves are shown in Fig. 8.

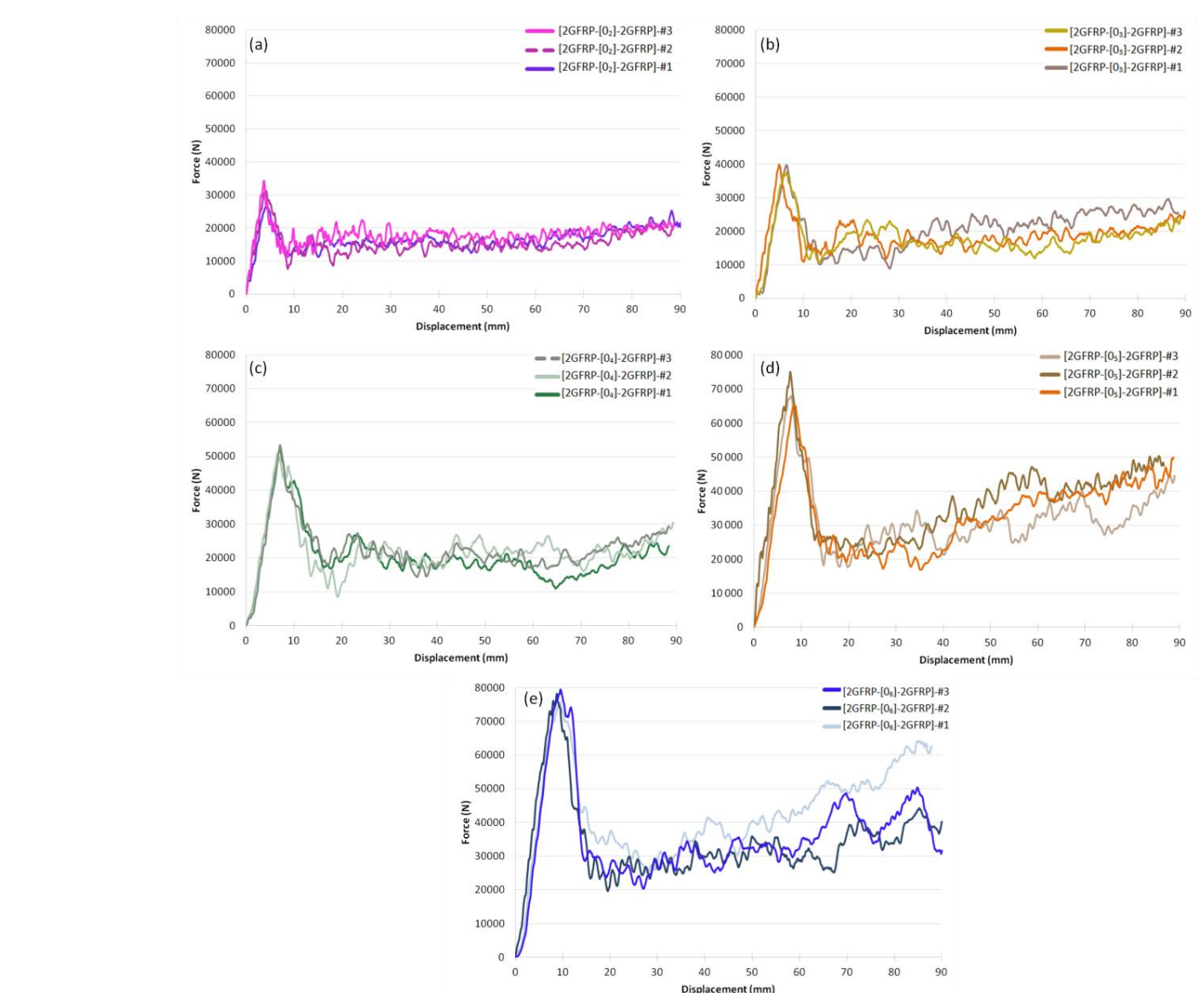

Fig. 8: Dynamic force-displacement curves for tubes (a) [2GFRP-[02]-2GFRP] (b) [2GFRP-[0 3]-2GFRP] (c) [2GFRP-

[04]-2GFRP] (d) [2GFRP-[05]-2GFRP] (e) [2GFRP-[06]-2GFRP]

177 carbon skins, for five and six layers of poplar, the crushing force is no longer constant and rises in the

178 plateau phase as the crushing increases. The compaction of the interior debris may be responsible for

179 this rise. The peak load, the plateau force and, therefore, the energy absorbed increase with the number 180 of 1214 layers, (Tab. 3).

\begin{tabular}{c|cc|cccc|c|c|} 
& $\mathbf{g}$ & $\mathbf{m m}$ & $\mathbf{N}$ & $\mathbf{m m}$ & $\mathbf{N}$ & $\mathbf{I}$ & $\mathbf{J}$ & $\mathbf{J} / \mathbf{g}$ \\
& Mass & Thickness & $\mathbf{F}_{\max }$ & $L_{\text {plateau }}$ & $\mathbf{F}_{\text {plateau }}$ & CFE & EA $_{\text {tot_80mm }}$ & SEA plateau \\
\hline [2GFRP-[02]-2GFRP] -\#1 & 46.5 & 2.86 & 26574 & 82.0 & 16725 & 0.63 & 1284 & 42.8 \\
[2GFRP-[02]-2GFRP] - \#2 & 47.9 & 2.99 & 31163 & 82.3 & 14695 & 0.47 & 1203 & 36.5
\end{tabular}




\begin{tabular}{|c|c|c|c|c|c|c|c|c|}
\hline [2GFRP-[02]-2GFRP] - \#3 & 48.0 & 2.90 & 34353 & 82.3 & 17956 & 0.52 & 1428 & 44.4 \\
\hline Average & 47.5 & 2.92 & 30697 & 82.2 & 16459 & 0.54 & 1305 & 41.2 \\
\hline Standard deviation & 0.8 & 0.07 & 3910 & 0.2 & 1647 & 0.08 & 114 & 4.2 \\
\hline [2GFRP-[03]-2GFRP] - \#1 & 58.4 & 4.25 & 39771 & 75.0 & 20827 & 0.53 & 1612 & 40.8 \\
\hline [2GFRP-[03]-2GFRP] - \#2 & 58.1 & 3.98 & 39910 & 79.7 & 18221 & 0.46 & 1462 & 37.2 \\
\hline [2GFRP-[03]-2GFRP] - \#3 & 59.6 & 4.11 & 37706 & 77.7 & 17228 & 0.46 & 1388 & 34.4 \\
\hline Average & 58.7 & 4.11 & 39129 & 77.5 & 18759 & 0.48 & 1487 & 37.5 \\
\hline Standard deviation & 0.8 & 0.14 & 1234 & 2.4 & 1859 & 0.04 & 114 & 3.2 \\
\hline [2GFRP-[04]-2GFRP] - \#1 & 71.6 & 5.22 & 52201 & 72.2 & 18713 & 0.36 & 1647 & 33.8 \\
\hline [2GFRP-[04]-2GFRP] - \#2 & 71.6 & 5.11 & 51071 & 75.9 & 21046 & 0.41 & 1760 & 36.1 \\
\hline [2GFRP-[04]-2GFRP] - \#3 & 71.9 & 5.05 & 53294 & 72.1 & 21229 & 0.40 & 1774 & 36.3 \\
\hline Average & 71.7 & 5.13 & 52189 & 73.4 & 20329 & 0.39 & 1727 & 35.4 \\
\hline Standard deviation & 0.2 & 0.09 & 1112 & 2.1 & 1403 & 0.03 & 70 & 1.4 \\
\hline [2GFRP-[05]-2GFRP] - \#1 & 85.2 & 6.09 & 65266 & 74.8 & 31963 & 0.49 & 2512 & 41.8 \\
\hline [2GFRP-[05]-2GFRP] - \#2 & 90.2 & 6.32 & 75043 & 73.8 & 35359 & 0.47 & 2856 & 46.2 \\
\hline [2GFRP-[05]-2GFRP] - \#3 & 87.9 & 6.28 & 68083 & 74.4 & 29835 & 0.44 & 2448 & 42.1 \\
\hline Average & 87.8 & 6.23 & 69464 & 74.3 & 32386 & 0.47 & 2605 & 43.3 \\
\hline Standard deviation & 2.5 & 0.12 & 5032 & 0.5 & 2786 & 0.03 & 220 & 2.5 \\
\hline [2GFRP-[06]-2GFRP] - \#1 & 104.3 & 7.54 & 75750 & 74.7 & 42479 & 0.56 & 3291 & 45.8 \\
\hline [2GFRP-[06]-2GFRP] - \#2 & 102.5 & 7.24 & 78173 & 74.3 & 31219 & 0.40 & 2648 & 37.6 \\
\hline [2GFRP-[06]-2GFRP] - \#3 & 104.4 & 7.38 & 79540 & 75.9 & 33778 & 0.42 & 2787 & 38.8 \\
\hline Average & 103.7 & 7.39 & 77821 & 75.0 & 35825 & 0.46 & 2908 & 40.7 \\
\hline Standard deviation & 1.1 & 0.15 & 1920 & 0.8 & 5902 & 0.09 & 338 & 4.4 \\
\hline
\end{tabular}

183 The failure mode is rather similar to that of the tubes with carbon fibre skins. In fact, in contact with the

184 crushing plate, the chamfer flattens out, introducing enough deformation of the glass fibres oriented at

$18590^{\circ}$ to force them to break. By breaking, they dissociate the tube into bundles and allow a splaying of

186 the inner and outer skins as well as the I214 layers (Fig. 9). 

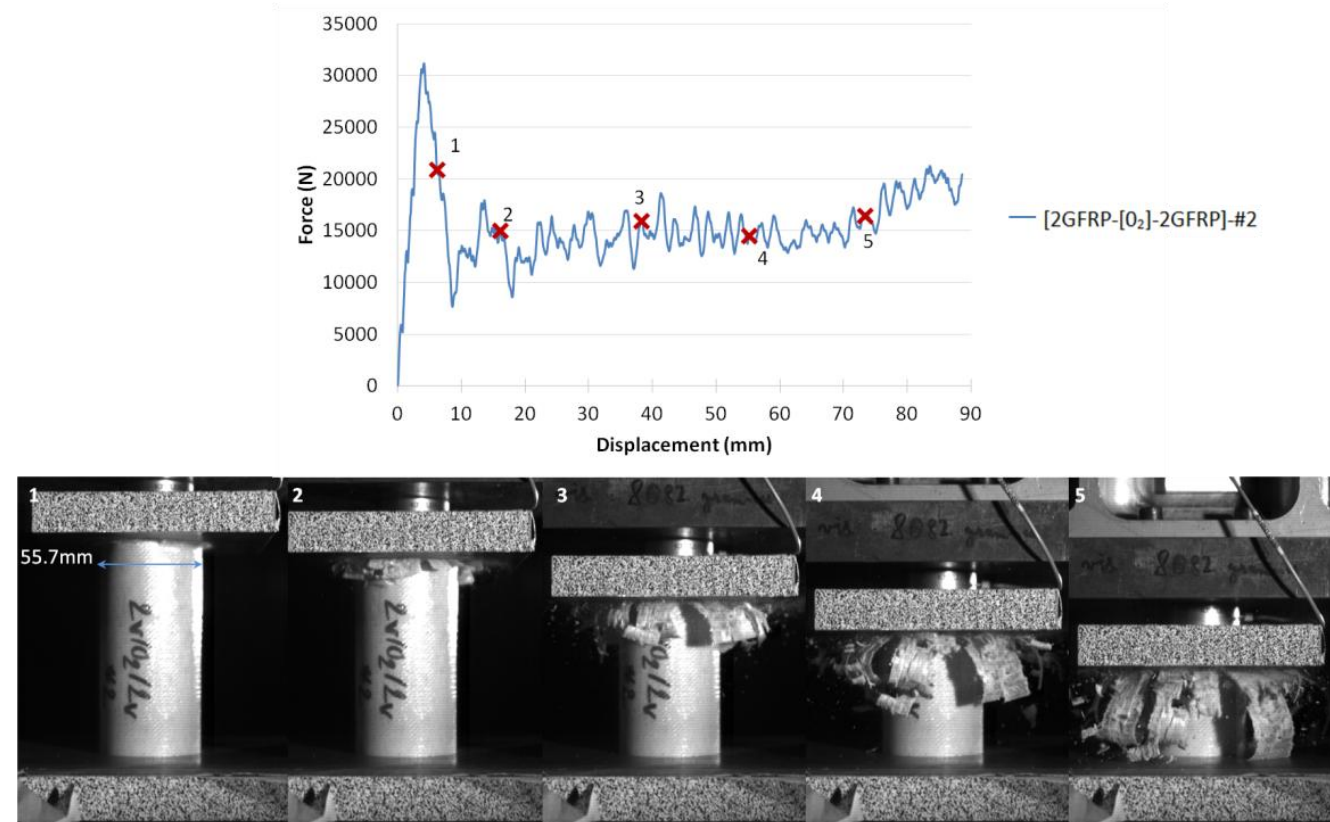

Fig. 9: Dynamic failure of tube [2GFRP-[02]-2GFRP]-\#2 and association of pictures and points on the force/ displacement curve.

191 The dissociation into bundles of the tube, accompanied by the splaying, leads to the formation of petals.

192 Fairly significant compaction was observed inside the tube (Fig. 10).

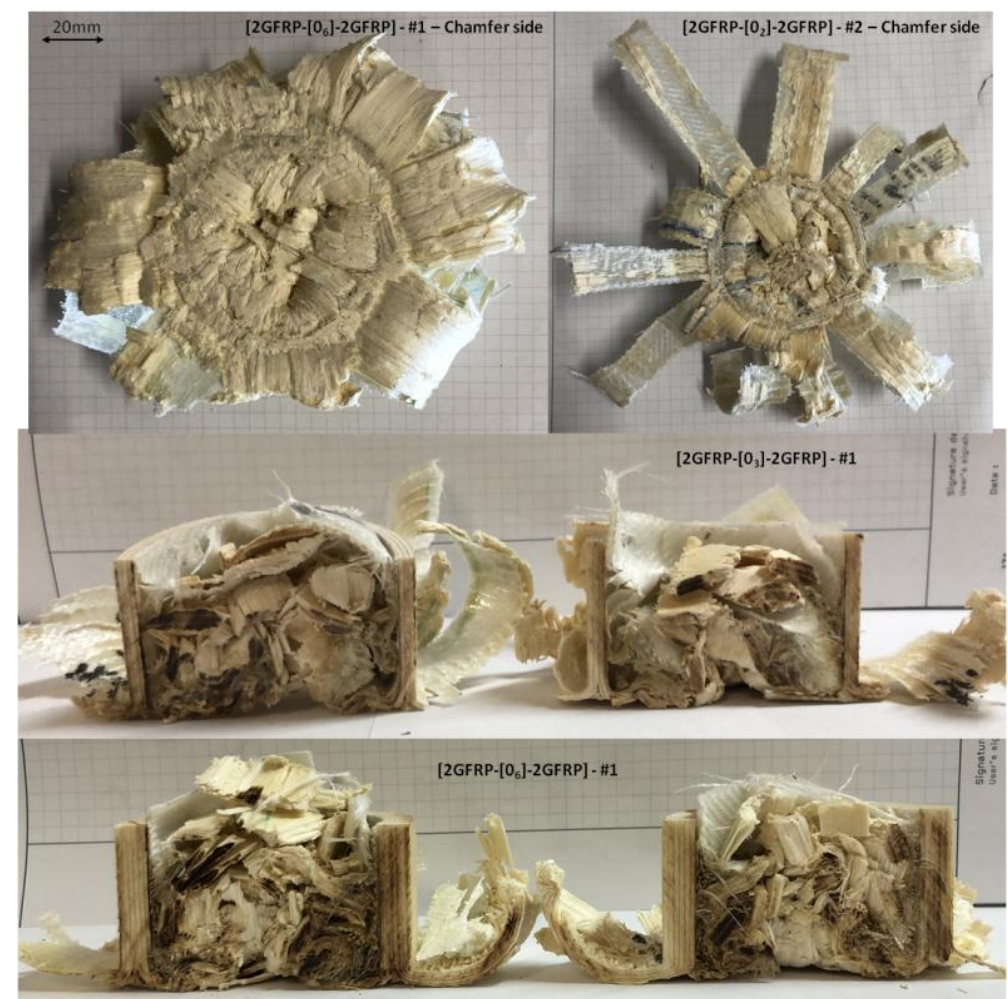

Fig. 10: Dynamic failure of tubes [2GFRP-[0 2 ]-2GFRP]-\#1 and [2GFRP-[0 6 ]-2GFRP]-\#1, and $1 / 2$ tubes [2GFRP-[0 3 2GFRP]-\#1 and [2GFRP-[06]-2GFRP]-\#1.

196 A slight debonding of the inner and outer skin and the 1214 layers was also observed. Although the 
19811 (a)). As the failure mechanisms were similar between the I214 ply configurations, the peak effort and 199 the mean effort at the plateau level were plotted versus the section of the tubes (Fig. 11 (b)).
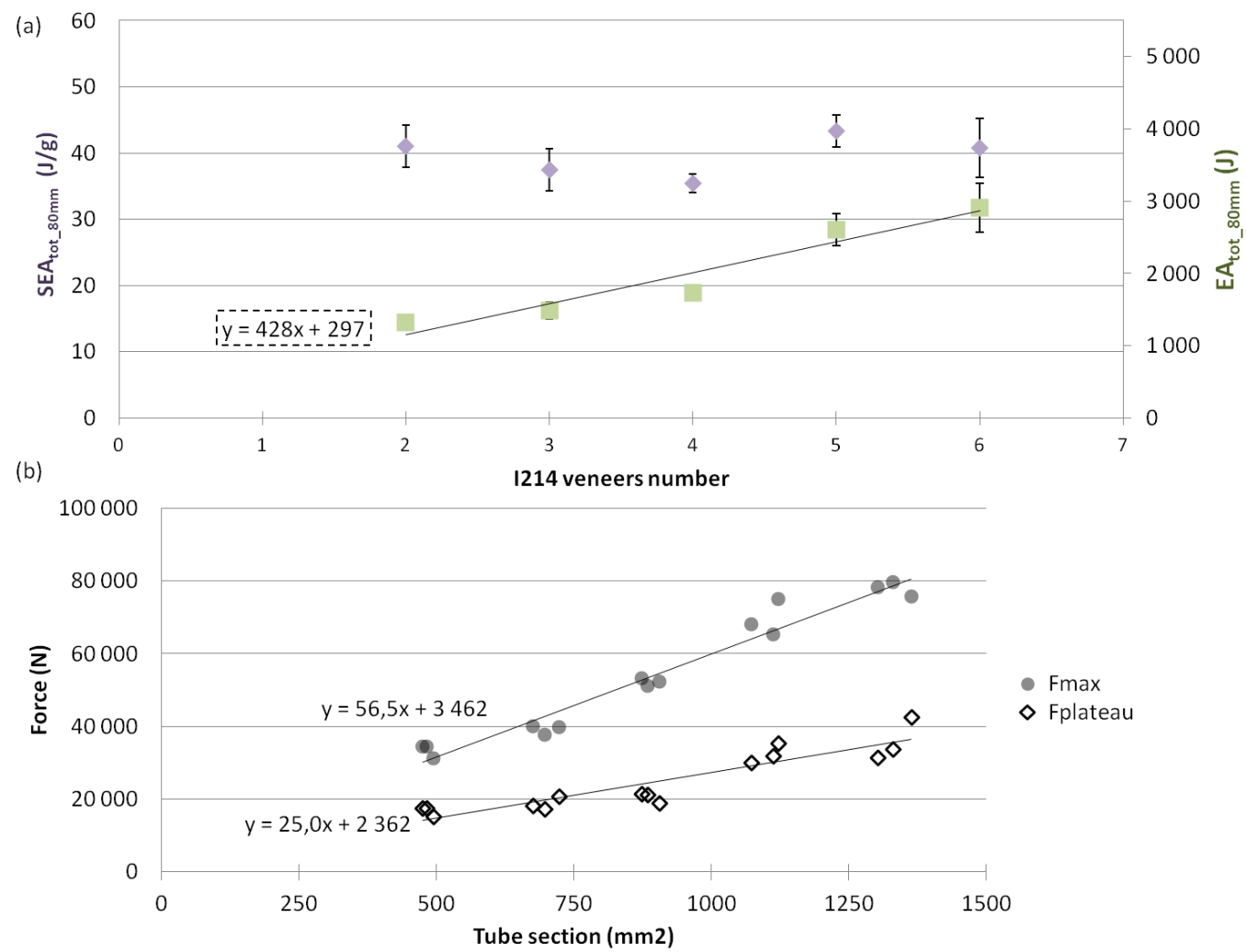

Fig. 11: Evolution of $E A_{\text {tot_ } 80 \mathrm{~mm}}$ and $S E A_{\text {tot_80mm }}$ versus the number of 1214 layers. (b) Maximum and plateau force versus tube sections for tubes with glass skins.

203 The increase in the energy absorbed for the three- and four-layer configuration was not significantly high 204 compared to the increase in the mass of the sandwich and, therefore, the SEA decreased from $40.8 \mathrm{~J} /$ $205 \mathrm{~g}$ on average to 37.5 then $35.4 \mathrm{~J} / \mathrm{g}$. The same observation was made for configurations with five and 206 six poplar layers, where the absorbed energy gained thanks to the additional poplar layers was insufficient to give a gain in SEA. The differences in SEA between the configurations having three and

208 four layers are difficult to explain. As with CFRP tubes, it was observed on several tubes that the failure 209 front could have a different number of 1214 folds splayed towards the inside of the tube on the same 210 plane. As the energy absorbed increases linearly with the number of $\mathrm{I} 214$ folds, it can be represented 211 by: $E A_{\text {tot_80mm }}=428 \times$ number layer ${ }_{I 214}+297$, where $428 \mathrm{~J}$ is the contribution of each 1214 212 layer and $297 \mathrm{~J}$ the contribution of the glass fibre skins. As with carbon fibre skins, the failure 
213 mechanisms were more efficient in the loading phase than in the plateau phase. The average crushing

214 stress of an 1214 ply surrounded by glass fibres was $25 \mathrm{MPa}$.

215

\subsection{Comparison between static and dynamic crushes}

\subsubsection{Tubes with carbon skins.}

218 In this part, the static and dynamic performances obtained on the configuration [2CFRP-[0N]-

2192 CFRP] $]_{2 \leq N \leq 6}$ are compared. But, first, the crushes of CFRP monolithic tubes with 4 carbon layers (Fig.

12) are studied in order to see the influence of the static and dynamic behaviour of wood coupled to

sandwich tubes $(8.8 \mathrm{~m} / \mathrm{s})$.

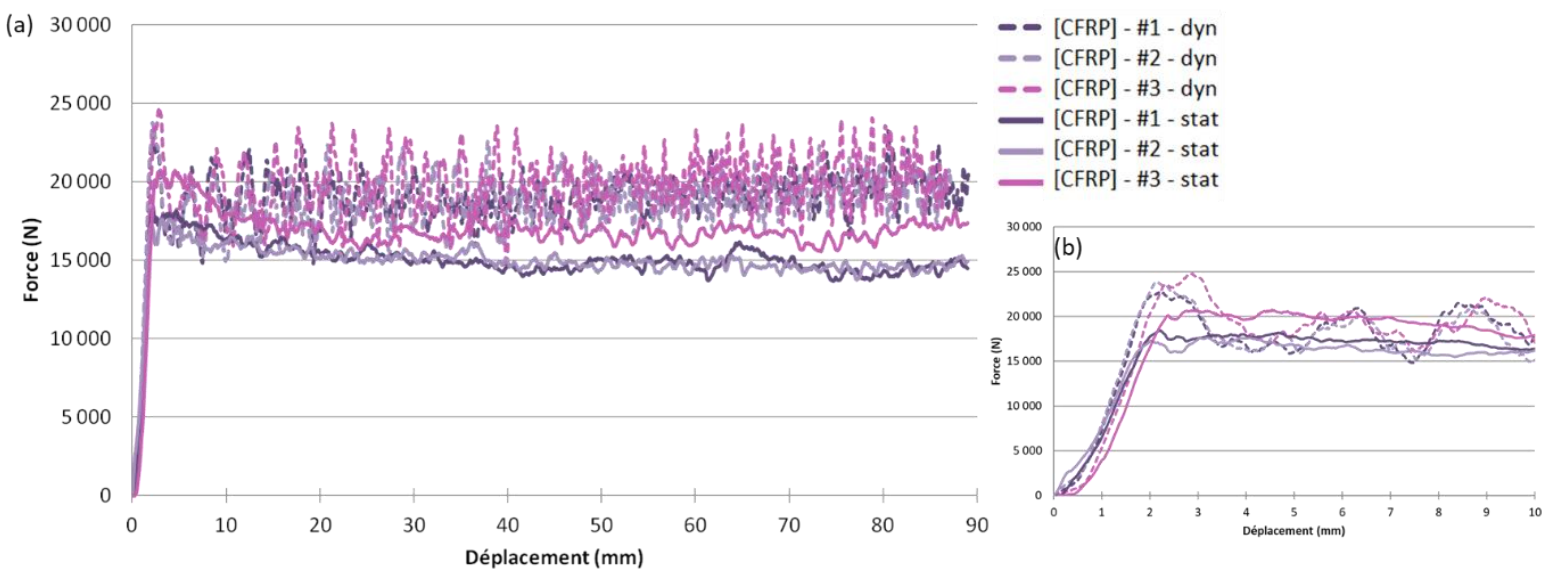

Fig. 12: (a) Static and dynamic crushing of tubes with carbon skins, (b) Zoom on initiation.

Again, the three crushing phases were found in both statics and dynamics. The oscillations were much static.

\begin{tabular}{|c|c|c|c|c|c|c|c|c|c|}
\hline & & $\begin{array}{c}\text { Mass } \\
\mathrm{g}\end{array}$ & $\begin{array}{c}\text { Thickness } \\
\mathrm{mm}\end{array}$ & $\begin{array}{c}F_{\max } \\
\mathbf{N}\end{array}$ & $\begin{array}{l}\text { Lplateau } \\
\mathrm{mm}\end{array}$ & $\begin{array}{c}\mathbf{F}_{\text {plateau }} \\
\mathbf{N}\end{array}$ & CFE & $\begin{array}{c}\text { EA tot_80mm } \\
\mathrm{J}\end{array}$ & $\begin{array}{c}\text { SEA } \\
\mathrm{J} / \mathrm{g}\end{array}$ \\
\hline \multirow{4}{*}{ 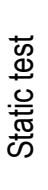 } & CFRP - I & 27.7 & 0.97 & 18434 & 79.2 & 14942 & 0.81 & 1203 & 64.6 \\
\hline & CFRP - II & 27.9 & 0.97 & 17603 & 80.7 & 14947 & 0.85 & 1196 & 63.7 \\
\hline & CFRP - III & 27.6 & 0.97 & 20729 & 79.3 & 16821 & 0.81 & 1340 & 71.8 \\
\hline & Average & 27.7 & 0.97 & 18922 & 79.7 & 15570 & 0.82 & 1247 & 66.7 \\
\hline
\end{tabular}




\begin{tabular}{|c|c|c|c|c|c|c|c|c|c|}
\hline & Standard deviation & 0.2 & 0.00 & 1619 & 0.8 & 1083 & 0.02 & 81 & 4.5 \\
\hline \multirow{5}{*}{ 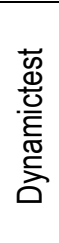 } & CFRP - I & 27.5 & 0.97 & 23232 & 85.6 & 19060 & 0.82 & 1499 & 80.9 \\
\hline & CFRP - II & 27.7 & 0.99 & 23783 & 82.9 & 18897 & 0.79 & 1491 & 79.8 \\
\hline & CFRP - III & 27.7 & 0.97 & 24780 & 84.0 & 19789 & 0.80 & 1557 & 83.2 \\
\hline & Average & 27.6 & 0.98 & 23932 & 84.2 & 19249 & 0.80 & 1516 & 81.3 \\
\hline & Standard deviation & 0.1 & 0.01 & 785 & 1.3 & 475 & 0.01 & 36 & 1.7 \\
\hline
\end{tabular}

Tab. 4: Results for static and dynamic crush of monolithic [CFRP] tubes.

231 The gain in specific energy absorption in dynamic tests was14.6 J/g. The dynamic performance of

232 carbon tubes was thus higher than in the static situation. The failure mode between statics and

233 dynamics was also different. In static conditions, the damage was caused by the progressive formation

234 of petals via splaying (Fig. 13). In dynamics, the post-mortem observation did not reveal whether the

235 numerous debris generated during the test were created by splaying or by fragmentation. Viewing the

236 videos obtained by the fast cameras did not decide this point either. The [CFRP] tubes were therefore

237 cut in half in order to observe the failure front under the microscope (Fig. 14).

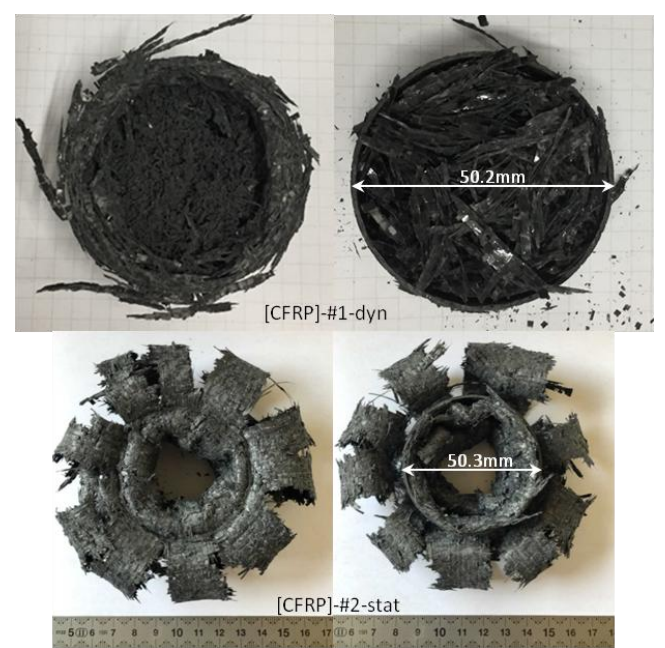

Fig. 13: Static and dynamic [CFRP] post-mortem failure pattern (chamfered side of the tube: photo on left; top of the tube: photo on right) 


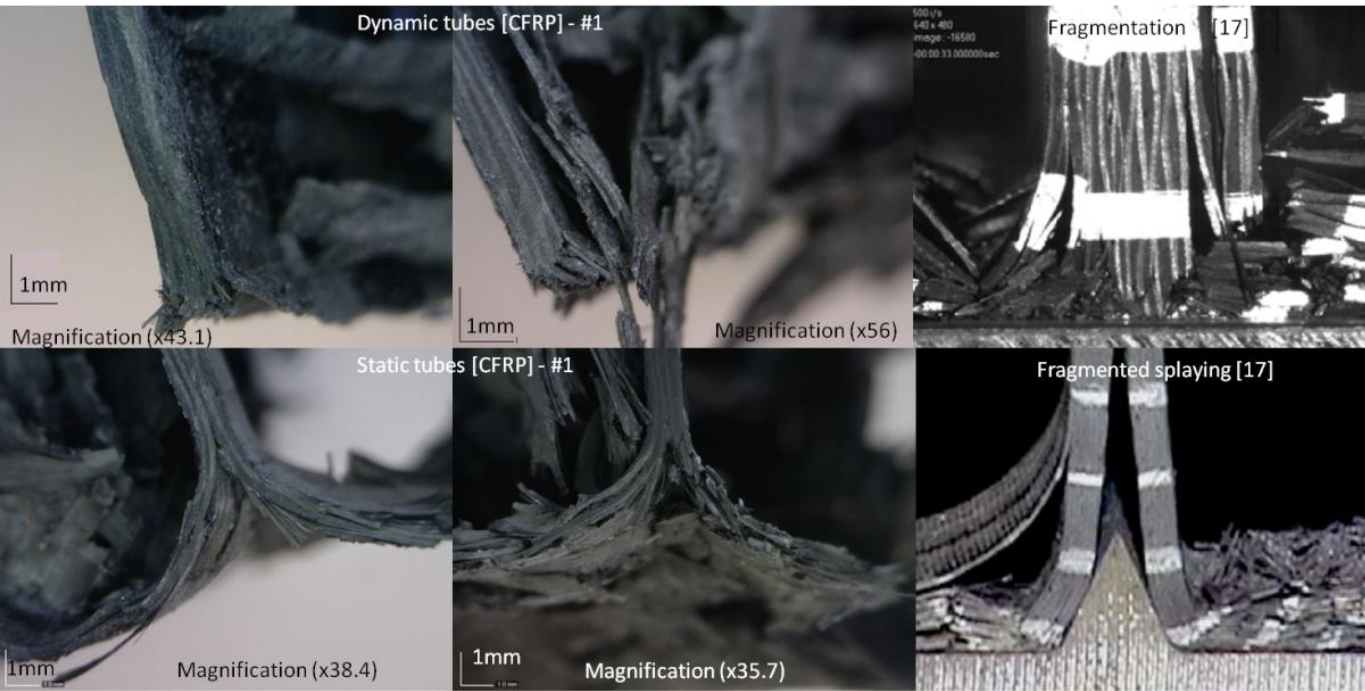

Fig. 14: Comparison of static and dynamic failure patterns of [CFRP] tube via microscopic observation (Right from [31]).

244 The static front shows splaying accompanied by failures in the laminate similar to the failure mode

245 obtained by Guillon and called fragmented splaying [31]. Concerning the dynamic failure front, the

246 absence of central cracking indicates more a classical dynamic failure mode of fragmentation which can

247 be explained by a more fragile behaviour of the carbon fibres or the matrix with the increase in the strain

248 rate.

249 Now, the results for the sandwich tubes are discussed. The averaged [2CFRP- [ON] $-2 \mathrm{CFRP}] 2 \leq \mathrm{N} \leq 6$

$250\left[2 \mathrm{CFRP}-\left[\mathrm{O}_{\mathrm{N}}\right]-2 \mathrm{CFRP}\right]_{2 \leq \mathrm{N} \leq 6}$ curves are superimposed in Fig. 15.

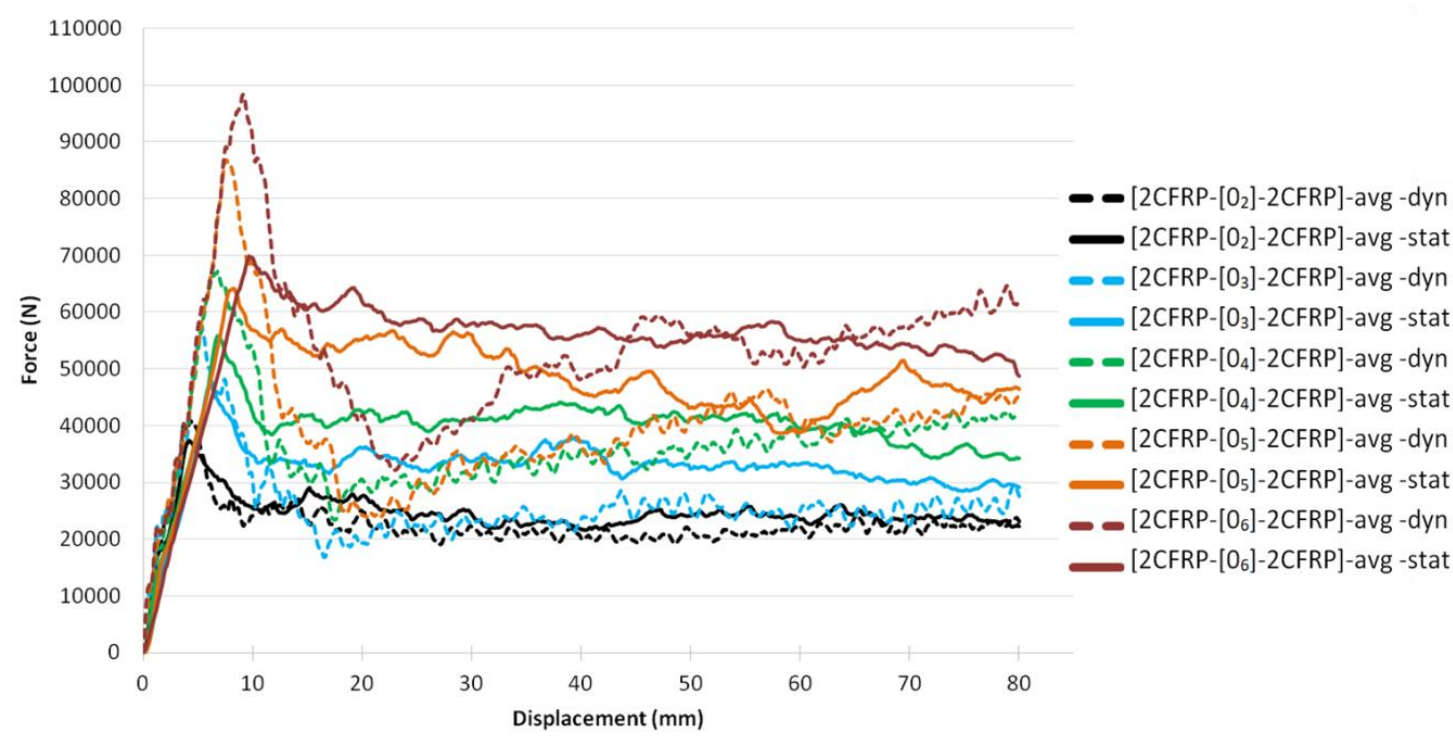

Fig. 15: Mean dynamic and static force-displacement curves of sandwich tubes [2CFRP-[0n]-2CFRP $]_{2 \leq n \leq 6}$ 
253 The peak load is much higher in dynamic than in static $(98,466 \mathrm{~N}$ for six poplar layers in dynamic versus

$25470,074 \mathrm{~N}$ in static, for example). An examination of the crushing plateau shows that the dynamic levels

255 are lower than the static in each configuration. Thus, the dynamic CFE (varying from 0.41 to 0.57 ) is

256 degraded in comparison to the static (varying from 0.63 to 0.85 ). The second observation concerns the

257 transition phase, which differs from dynamic to static. In fact, in dynamics, after the peak load, the force

258 decreases during about ten millimetres of crushing and then reaches the plateau. The transition phase

259 is thus longer in dynamics than in statics. In addition, in dynamics, the plateau increases as the crushing progresses, more particularly for the configurations having four, five or six poplar layers. This is probably

in connection with the compaction of the debris inside the tube, which results in a larger volume of debris for globally the same overall dimensions of the tube. In both statics and dynamics, the energy absorbed increased linearly with the number of 1214 layers (Fig. 17). The equation shows that the contribution of a wood ply is slightly greater in dynamics $(606 \mathrm{~J})$ than in statics $(576 \mathrm{~J})$. The y-intercept provides information on how CFRP skins behave. They can be seen to absorb less energy dynamics $(412 \mathrm{~J})$ than in statics $(851 \mathrm{~J})$. In dynamic tests, the CFRP tubes alone absorbed an energy of $1516 \mathrm{~J}$, showing that they work better on their own than as the skin of sandwich tubes. However, CFRP skins stabilized the 1214 layers oriented at $0^{\circ}$ thus improving the crash behaviour of the sandwich. The average value as a function of the number of 1214 layers of the dynamic SEA is also more dispersed

\section{0 than the static SEA.}

271

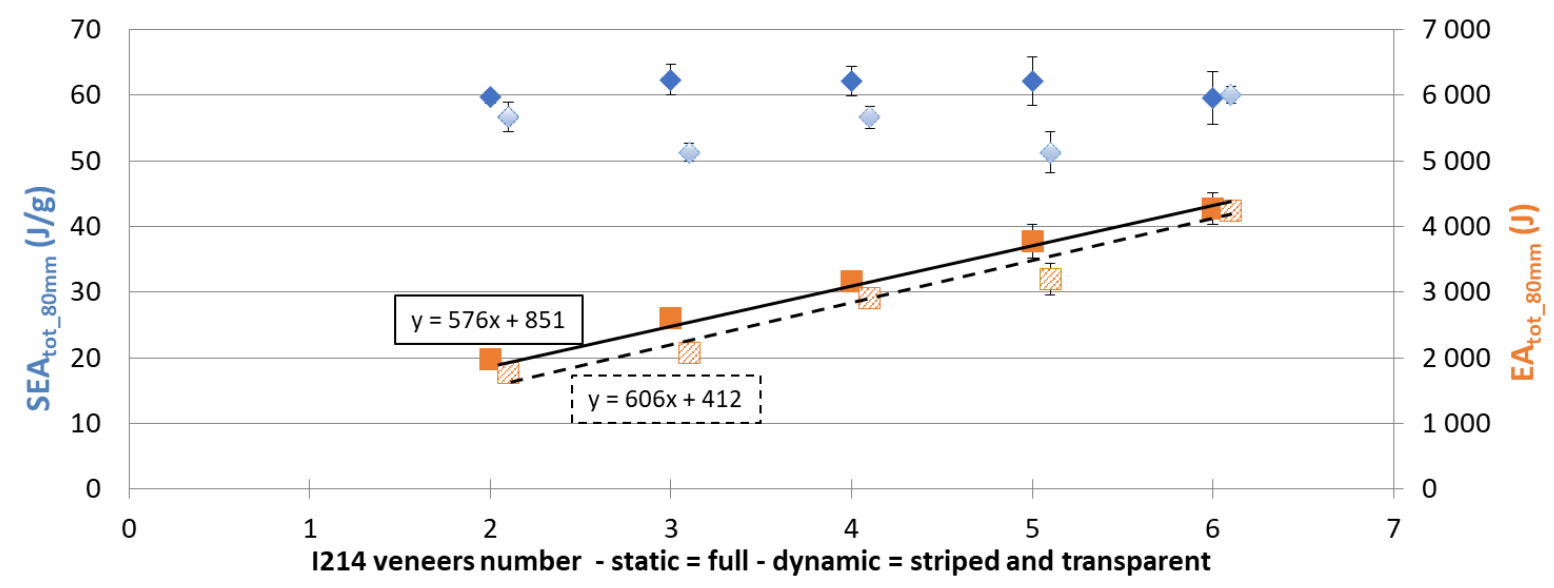


273

274

275 Whether CFE, absorbed energy or SEA is considered, the dynamic performance of these sandwich

276 tubes is slightly lower than their static performance. The average crushing stress with carbon fibre skins

277 is almost identical between the static (37.2 MPa) and dynamic (34.9 MPa) regimes. A comparison of the

278 static and dynamic failure modes shows that the overall failure is similar: splaying with the formation of

279 petals (Fig. 18 and Fig. 19). However, certain phenomena, such as local buckling, are no longer present

280 in the dynamic failure mode. Finally, it should also be noted that the compaction of the debris inside the

281 tube is greater in dynamics (Fig. 19).
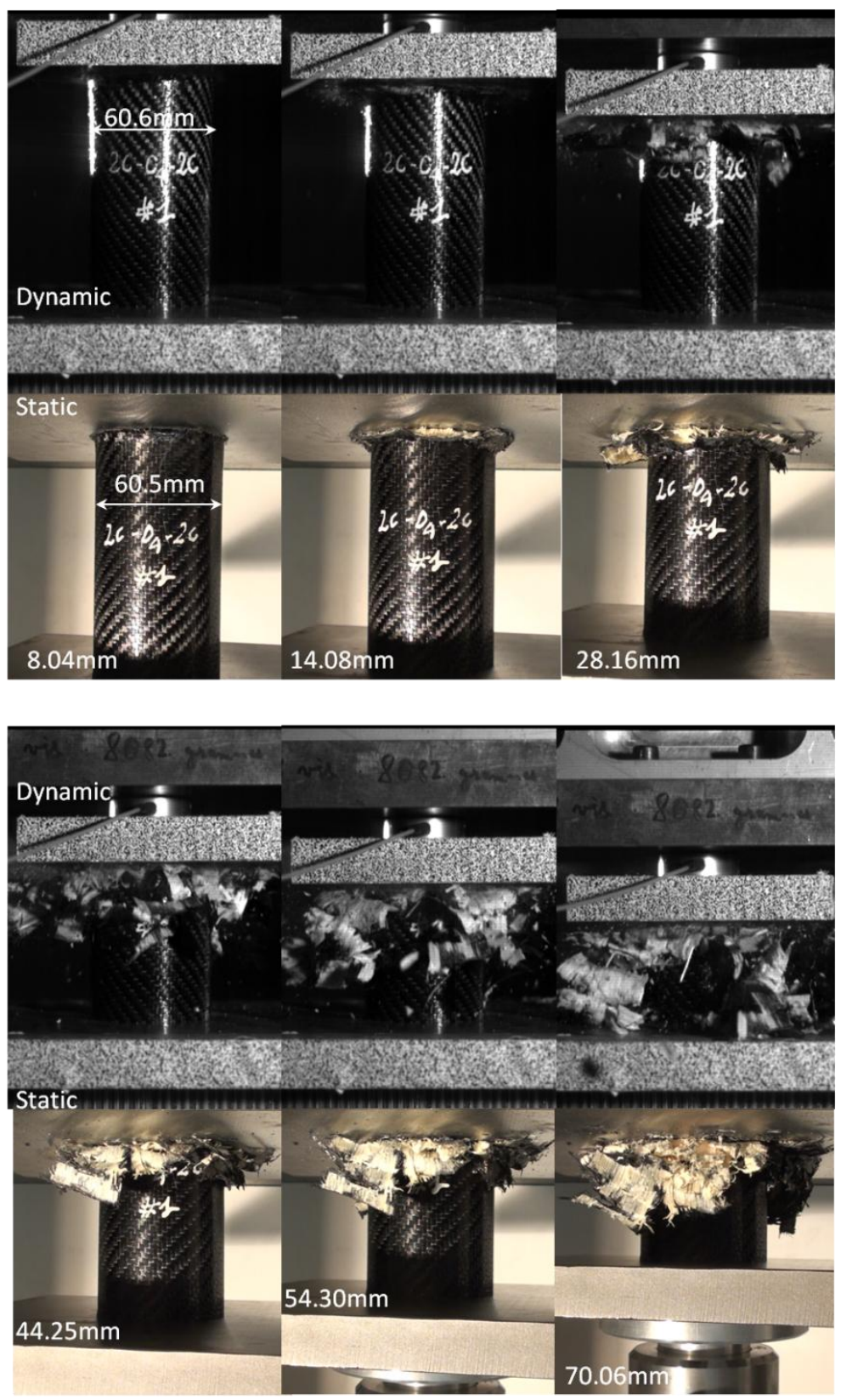
Fig. 17: Static and dynamic comparison of the failure mode of the tube [2CFRP-[04]-2CFRP]-\#1 at iso-displacement (the static images have been turned).
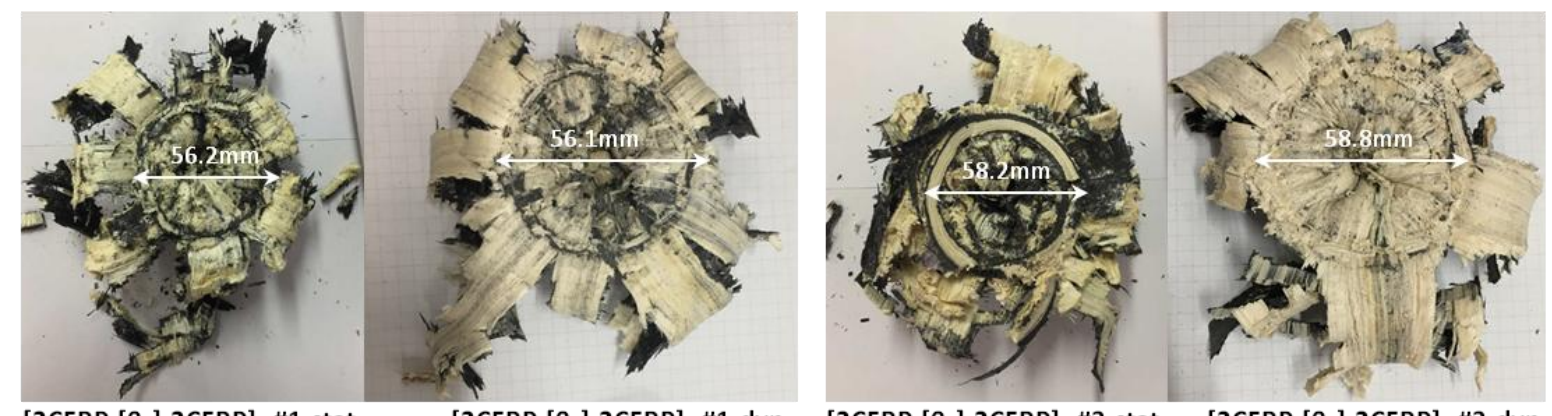

[2CFRP-[0 $\left.{ }_{2}\right]$-2CFRP]-\#1-stat

[2CFRP-[0 2$]-2$ CFRP]-\#1-dyn

[2CFRP-[0 $\left.0_{4}\right]-2$ CFRP]-\#3-stat [2CFRP-[0 $\left.0_{4}\right]-2$ CFRP]-\#3-dyn
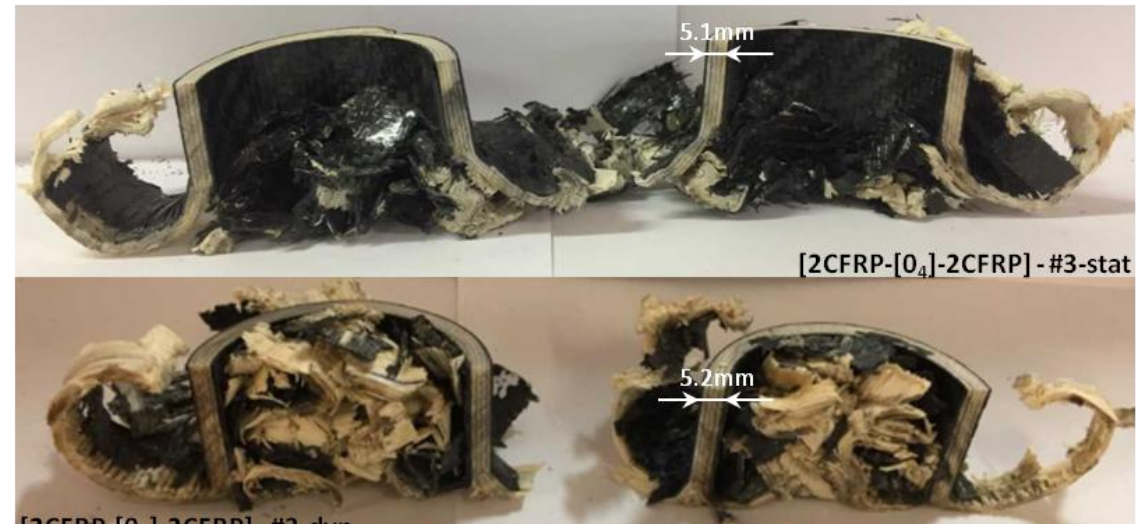

[2CFRP-[0 $\left.0_{4}\right]$-2CFRP]-\#3-stat

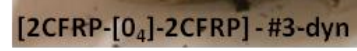

Fig. 18: Static and dynamic comparison of post-mortem failure patterns for tubes with carbon skins.

\subsubsection{Tubes with glass skins}

289 The static and dynamic performance of the sandwiches [2GFRP-[0N]-2GFRP] $2 \leq N \leq 6$. were compared.

290 First, the crushes of monolithic GFRP tubes with four GFRP layers (Fig. 12) were studied to investigate

291 the influence of the static and dynamic behaviour of wood coupled with carbon fibres.
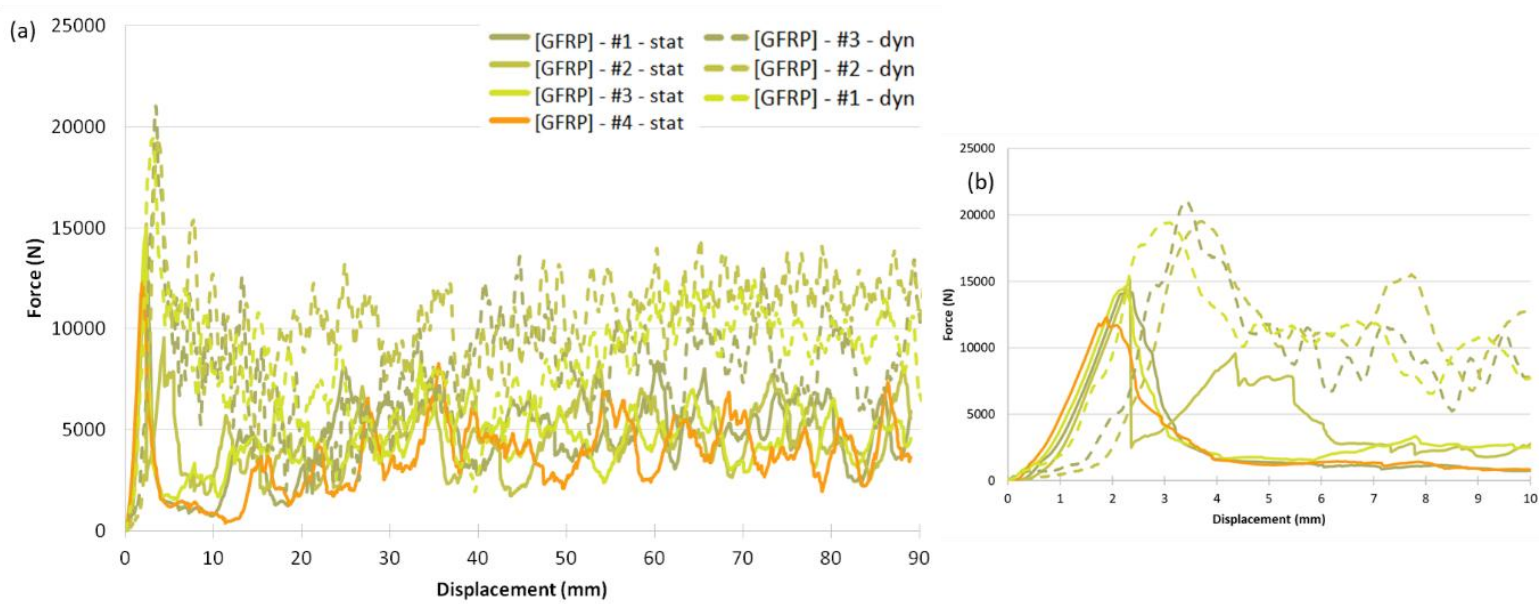

Fig. 19: (a) Static and dynamic crushing of monolithic glass tubes (b) Focus on initiation 
294 Once again, the three classical phases were found in static and dynamic. On the overall reading of the 295 crushing curves, an improvement in the energy absorption capacities of the dynamic glass fibre tubes 296 was observed. The average plateau force was almost doubled, resulting in the doubling of the energy 297 absorbed and the SEA (Tab. 5).

\begin{tabular}{|c|c|c|c|c|c|c|c|c|c|}
\hline & & $\begin{array}{c}\text { Mass } \\
\mathrm{g}\end{array}$ & $\begin{array}{c}\text { Thickness } \\
\mathrm{mm}\end{array}$ & $\begin{array}{c}F_{\max } \\
\mathbf{N}\end{array}$ & $\begin{array}{c}\text { Lplateau } \\
\mathrm{mm}\end{array}$ & $\begin{array}{c}F_{\text {plateau }} \\
\mathbf{N}\end{array}$ & $\begin{array}{c}\text { CFE } \\
I\end{array}$ & $\begin{array}{c}E A_{\text {tot_80mm }} \\
\mathrm{J}\end{array}$ & $\begin{array}{c}\text { SEA } A_{\text {tot_80mm }} \\
\mathrm{J} / \mathrm{g}\end{array}$ \\
\hline \multirow{6}{*}{ 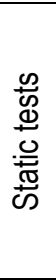 } & [GFRP] - \#1 & 24.2 & 0.65 & 14179 & 76.0 & 4860 & 0.34 & 369 & 22.6 \\
\hline & [GFRP] - \#2 & 24.3 & 0.68 & 15178 & 83.3 & 4476 & 0.29 & 363 & 22.2 \\
\hline & [GFRP] - \#3 & 23.7 & 0.67 & 14617 & 77.5 & 4674 & 0.32 & 359 & 22.5 \\
\hline & [GFRP] - \#4 & 23.7 & 0.67 & 12275 & 74.7 & 3985 & 0.32 & 291 & 18.3 \\
\hline & Average & 24.0 & 0.67 & 14062 & 77.9 & 4499 & 0.32 & 364 & 21.4 \\
\hline & Standard deviation & 0.3 & 0.01 & 1260 & 3.8 & 377 & 0.02 & 37 & 2.1 \\
\hline \multirow{5}{*}{ 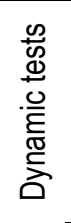 } & [GFRP] - \#1 & 24.8 & 0.70 & 19430 & 88.4 & 8230 & 0.42 & 656 & 39.6 \\
\hline & [GFRP] - \#2 & 25.0 & 0.75 & 19525 & 87.1 & 10329 & 0.53 & 793 & 47.5 \\
\hline & [GFRP] - \#3 & 25.1 & 0.72 & 21015 & 85.4 & 7923 & 0.38 & 632 & 37.8 \\
\hline & Average & 25.0 & 0.72 & 19990 & 87.0 & 8827 & 0.44 & 694 & 41.6 \\
\hline & Standard deviation & 0.1 & 0.03 & 889 & 1.6 & 1310 & 0.08 & 87 & 5.2 \\
\hline
\end{tabular}
Tab. 5: Static and dynamic [GFRP] tube crush results.

299 The increase in absorbed energy and SEA can be explained by a difference in failure mode between

300 static and dynamic. During the static crush, large pieces of debris were created (of the order of a few 301 centimetres) accompanied by instability of the walls of the tube, leading to very little energy absorption.

302 In dynamics, the size of debris was much smaller (dust was visible on high speed camera images)

303 although some macroscopic debris was created (Fig. 21). Post-mortem observation of the dynamic

304 tubes showed the occasional presence of petals that were created by local splaying or via full-thickness 305 bending. 
316 Now, the results for the sandwich tubes are discussed. The averaged curves of static and dynamic test

Fig. 20: Static and dynamic [GFRP] tube post-mortem patterns (chamfered side of the tube: photo on the left; top of the tube: photo on the right)

Observation of the thickness of a half-tube [GFRP] under a microscope indicated the absence of a longitudinal crack (synonymous with splaying) and showed that the creation of debris took place by bending causing intralaminar cracks (Fig. 22). Therefore the dynamic and static failure mode was fragmentation, with smaller debris in dynamics, which dissipated more energy.

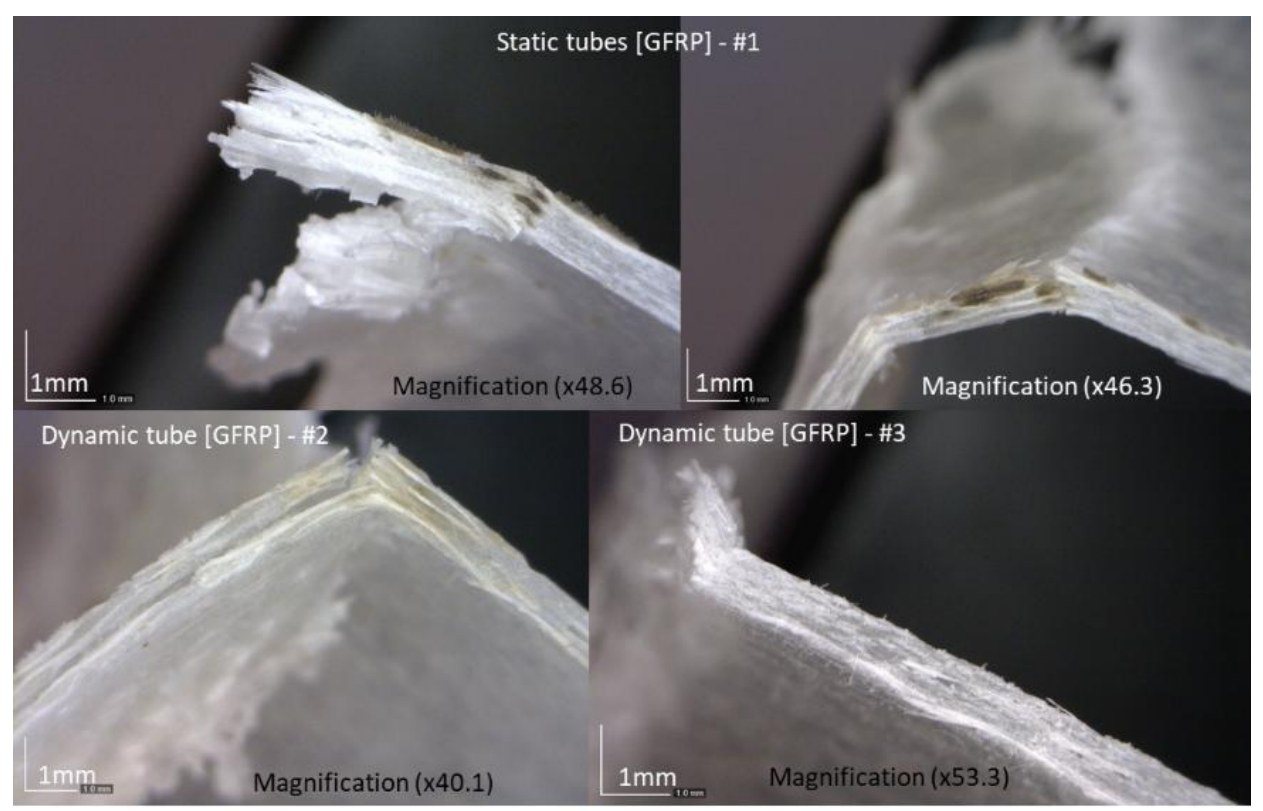

Fig. 21: Comparison of static and dynamic failure patterns of [GFRP] tubes via microscopic observation. results versus the number of poplar layers have been superimposed in Fig. 23.

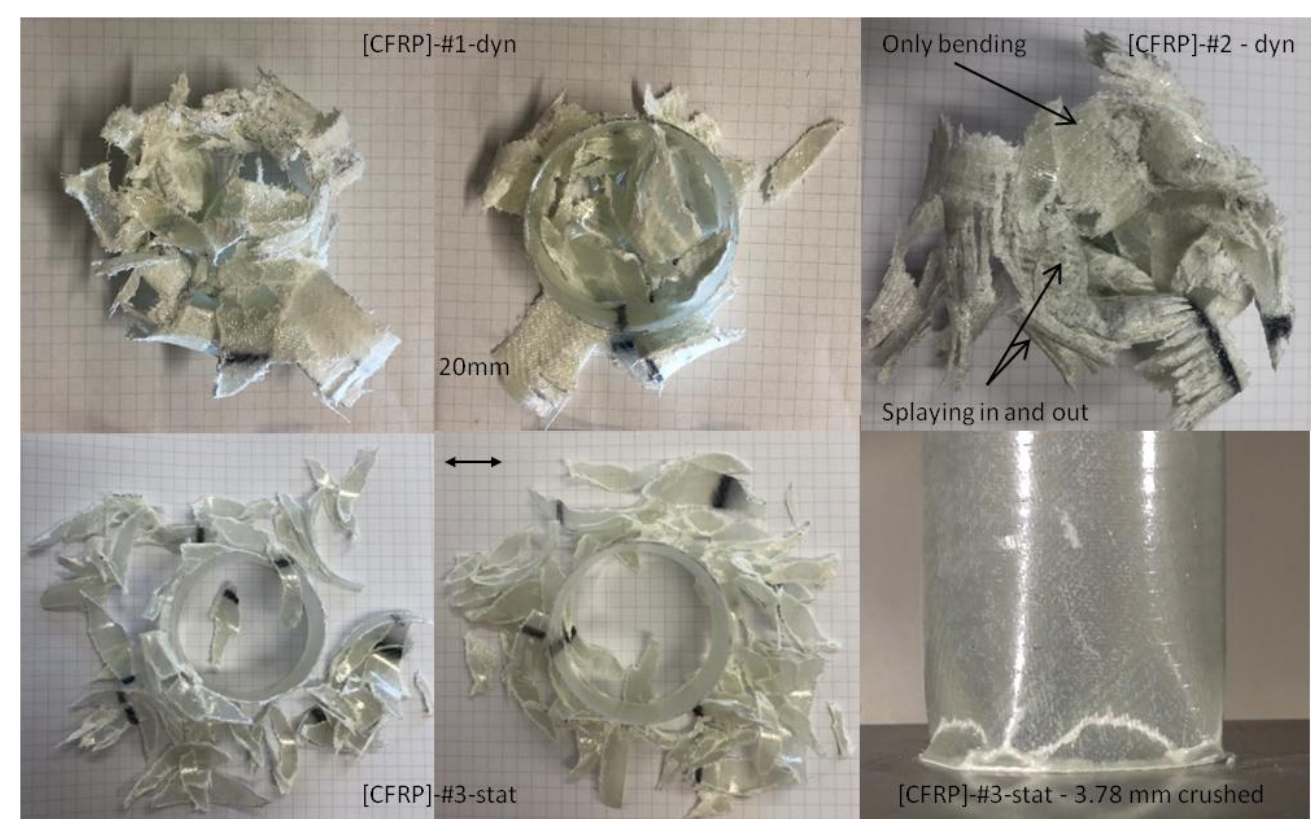




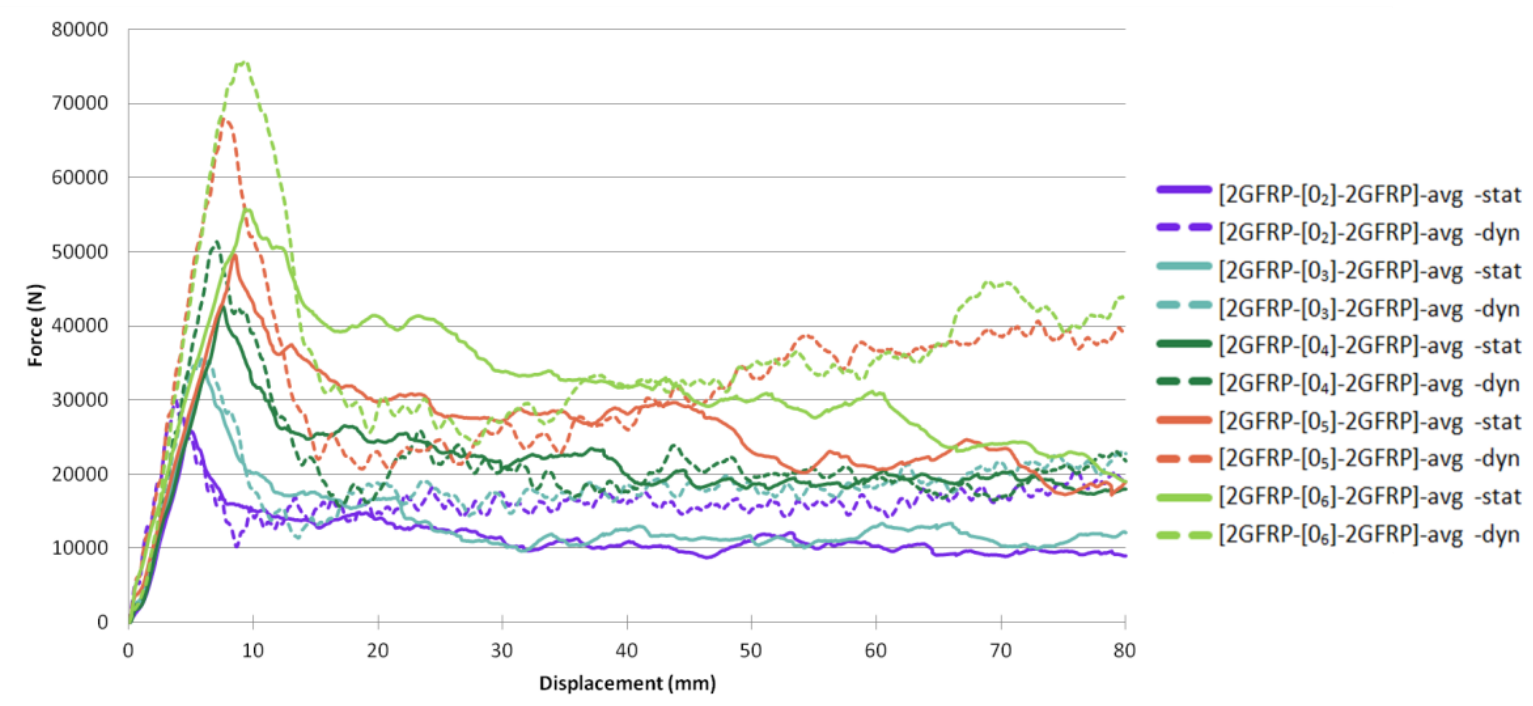

320 A first observation concerns the change of the apparent slope between static and dynamic conditions. In

321 dynamics, the slope is greater than in static (Fig. 23) for all configurations. As the pseudo-linear slope of 322 the glass fibre tubes also changed between the static and dynamic regimes, this behaviour can be 323 attributed to the 1214 poplar, the glass fibres or the coupling of the two materials. The second observation is that the performance of sandwich tubes with glass fibre skins was improved in dynamics (Fig.24).

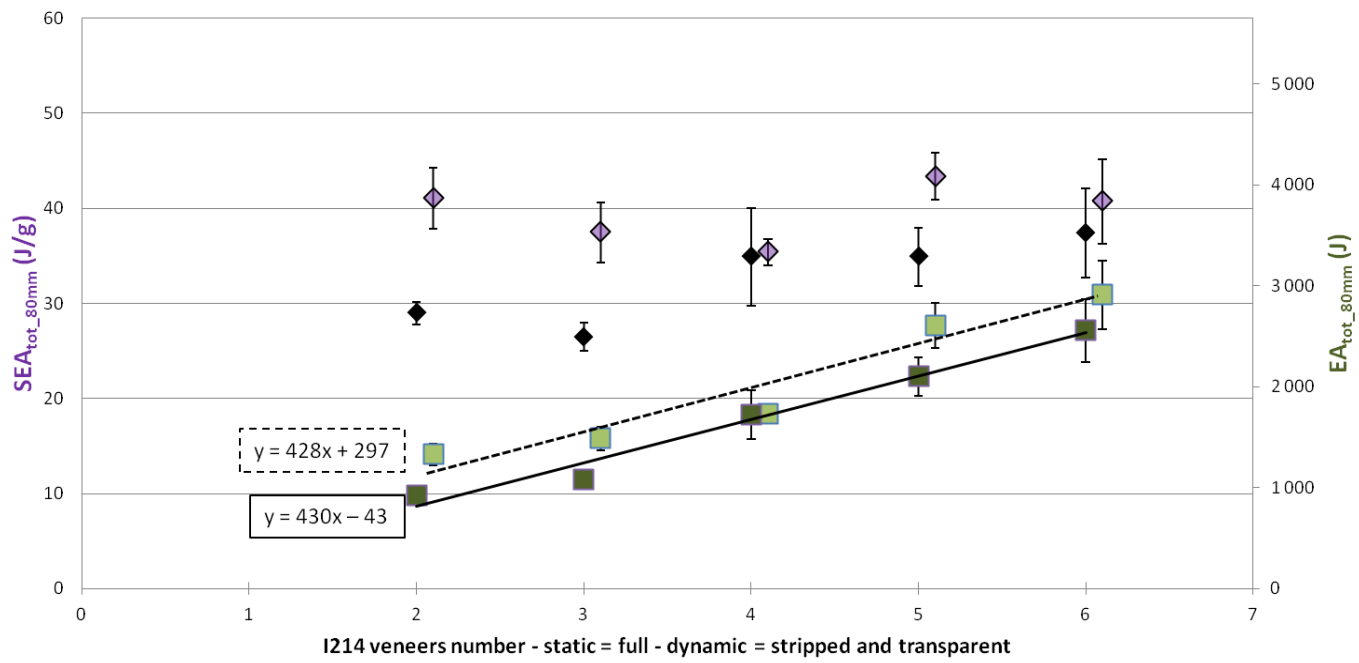

Fig. 24: Evolution of EAtot_80mm and SEAtot_80mm according to the number of 1214 plies in static and dynamic for tubes with glass skins.

The slope modelling the absorbed energy presented an identical director coefficient in dynamics and statics. In addition, the average crushing stress of an 1214 ply surrounded by glass fibres changed very

331 little or not at all between the static (24.3 MPa) and the dynamic (25 MPa) tests. The comparison of 
static and dynamic post-mortem failure patterns showed a fairly similar mode of failure with mainly the

333 formation of petals after splaying (Fig. 25). However, the local buckling observed in statics disappeared

334 in dynamics and the compaction of debris was much greater in dynamics than in statics, as for tubes

335 with carbon skins (Fig. 26). The debonding of interior fibreglass skins was also much greater in static

336 than in dynamic.
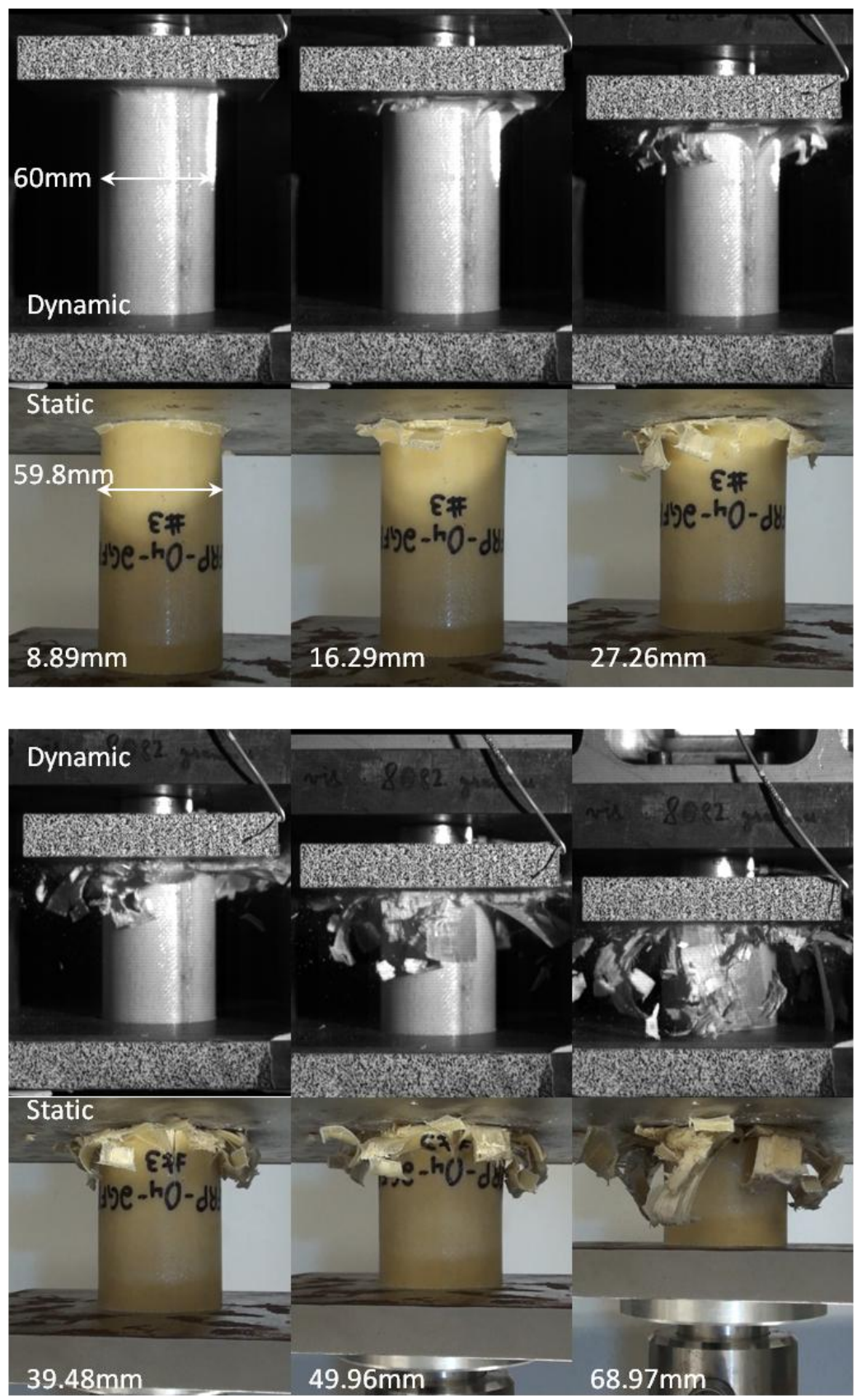

Fig. 25: Static and dynamic comparison of the failure mode of the tube [2GFRP-[04]-2GFRP]-\#3 at iso-displacement (the static images have been turned). 


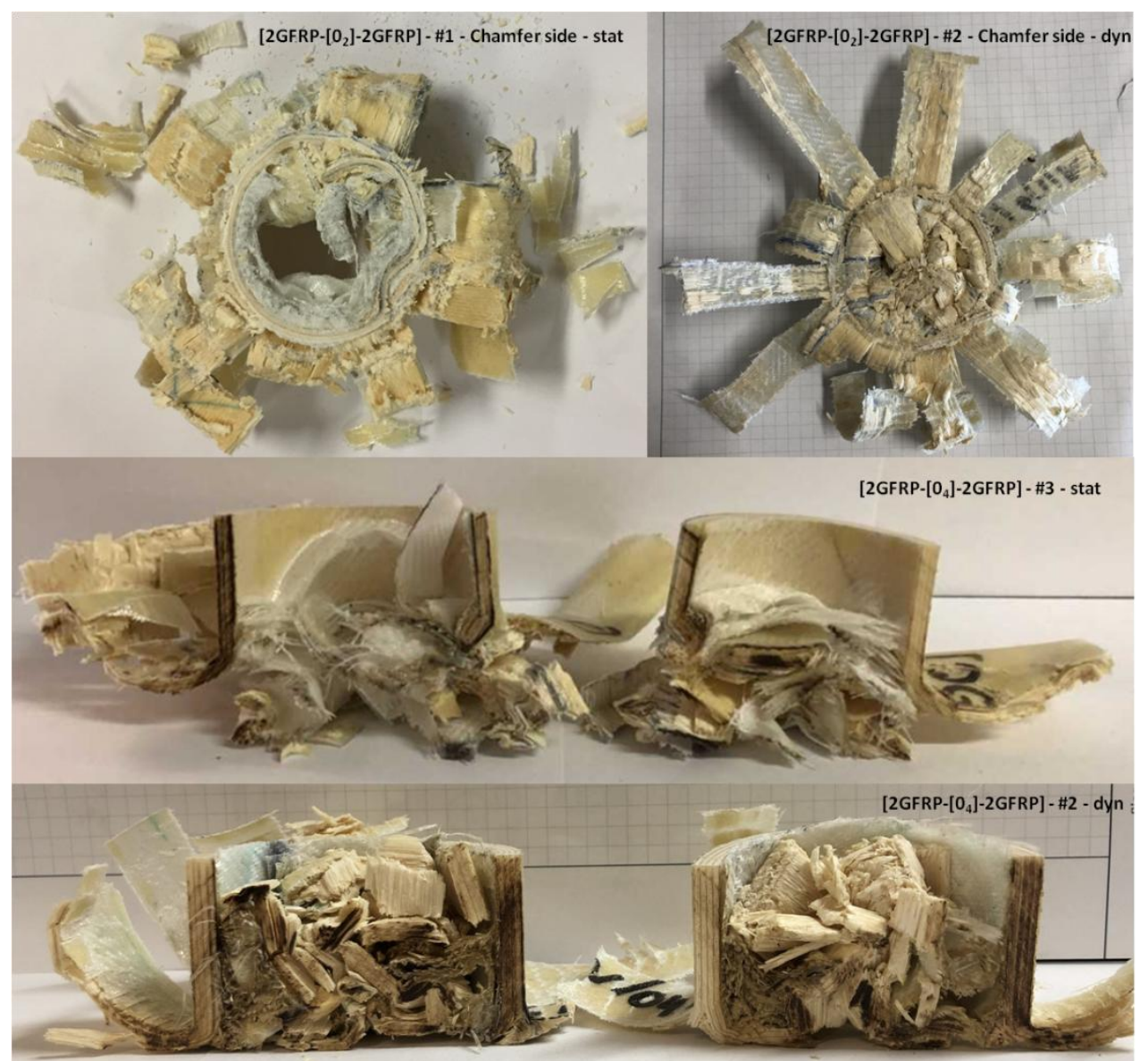

Fig. 26: Static and dynamic comparison of the post-mortem failure pattern for tubes with glass skins.

\subsection{Coupling gains between wood core and composite skins}

344 To assess the coupling effects, the approach adopted was as follows. The crushed tubes [CFRP] and

345 [GFRP] shown in Tab. 4 and Tab. 5 correspond to the equivalent of the outer and inner skins of

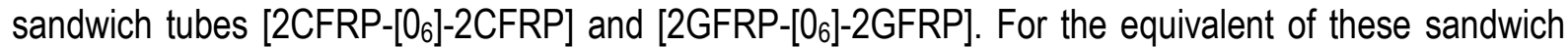
tubes using wood core alone, it was not possible to consider the poplar-only tubes [06] (6 layers in the longitudinal direction) as, due to a very unstable mode of failure, the possible contribution of the wood to the energy absorption was very low and not significant [29]. So the most stable configuration, still with six layers of poplar but with only four plies in the longitudinal direction $\left[90 / 0_{4} / 90\right]$ was considered for the reference of the wood core. By cumulating the crushing of the tubes [CFRP] (or [GFRP]) and the equivalent of the core $\left[90 / 0_{4} / 90\right]$, and comparing them to the direct crushing of the tubes [2CFRP-[06]2CFRP] (or [2GFRP-[06]-2GFRP]), the coupling effect was deduced. 
356 The results are presented in Fig. 27 and Tab. 6 and the results obtained in static [30] are recalled. A

357 gain of $41 \%$ can be noted for the strength of the plate, $35 \%$ for the energy absorbed and $40 \%$ for the

358 SEA, showing the interest of merging these materials. However, the gain is slightly lower than in static

359 conditions (Tab. 6). This slightly lower gain can be explained by the fact that the CFRP tube alone

360 shows an improvement in its dynamic SEA (+ $14.6 \mathrm{~J} / \mathrm{g})$, while the sandwich tube with carbon fibre skins

361 keeps an identical SEA (0.5 J/g difference).

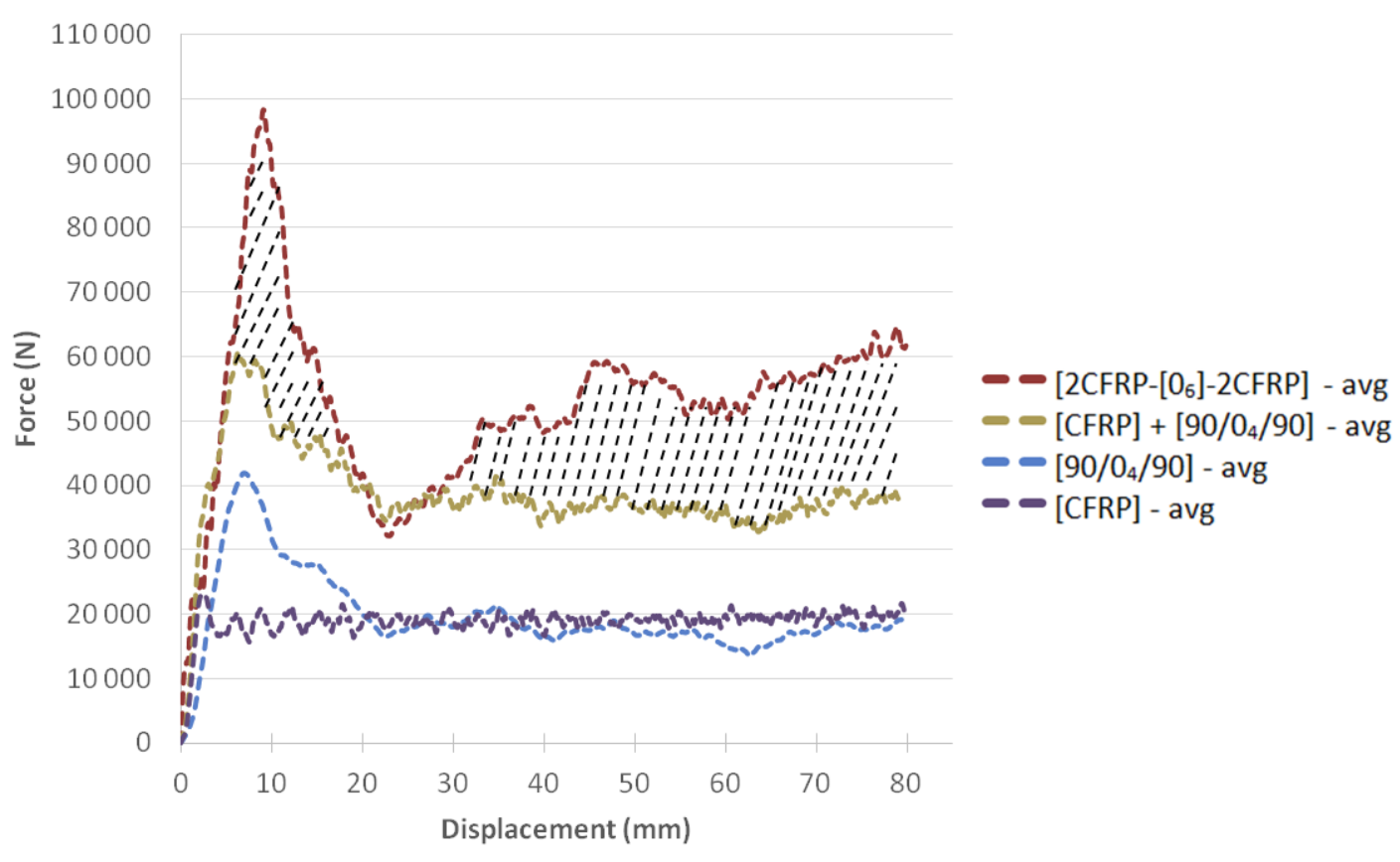

Fig. 27: Dynamic coupling for sandwich [2CFRP-[06]-2CFRP]

364

\begin{tabular}{|c|c|c|c|c|}
\hline & $\begin{array}{c}\text { F }_{\text {plateau }} \\
\mathbf{N}\end{array}$ & $\begin{array}{c}\mathrm{EA}_{\text {tot_80mm }} \\
\mathrm{J}\end{array}$ & $\begin{array}{c}\text { Mass } \\
\mathrm{g}\end{array}$ & $\begin{array}{c}\text { SEA } A_{\text {tot_80mm }} \\
\mathrm{J} / \mathrm{g}\end{array}$ \\
\hline $\begin{array}{c}{\left[90 / 0_{4} / 90\right]-\text { avg }} \\
{[\text { CFRP }]-\text { avg }} \\
{\left[90 / 0_{4} / 90\right]+[\text { CFRP }]-\text { avg }}\end{array}$ & $\begin{array}{l}21019 \\
15570 \\
36589\end{array}$ & $\begin{array}{l}1632 \\
1247 \\
2879\end{array}$ & $\begin{array}{c}76.6 \\
27.7 \\
104.3\end{array}$ & $\begin{array}{l}30.6 \\
66.7 \\
40.6\end{array}$ \\
\hline [2CFRP-[06]-2CFRP] - avg & 55551 & 4264 & 102.9 & 59.5 \\
\hline Coupling gain & $52 \%$ & $48 \%$ & & $47 \%$ \\
\hline $\begin{array}{c}{\left[90 / 0_{4} / 90\right] \text { - avg }} \\
{[\text { CFRP] - avg }} \\
{\left[90 / 0_{4} / 90\right]+[\text { CFRP }] \text { - avg }}\end{array}$ & $\begin{array}{l}17940 \\
19249 \\
37189\end{array}$ & $\begin{array}{l}1618 \\
1516 \\
3134\end{array}$ & $\begin{array}{c}72.8 \\
27.6 \\
100.4\end{array}$ & $\begin{array}{l}31.5 \\
81.3 \\
42.9\end{array}$ \\
\hline [2CFRP-[06]-2CFRP] - avg & 52459 & 4235 & 102.0 & 60.0 \\
\hline
\end{tabular}

Tab. 6: Gain obtained by coupling wood core and carbon skins. 
367 The dynamic coupling for glass skins is shown in Fig. 28 and Tab 7.

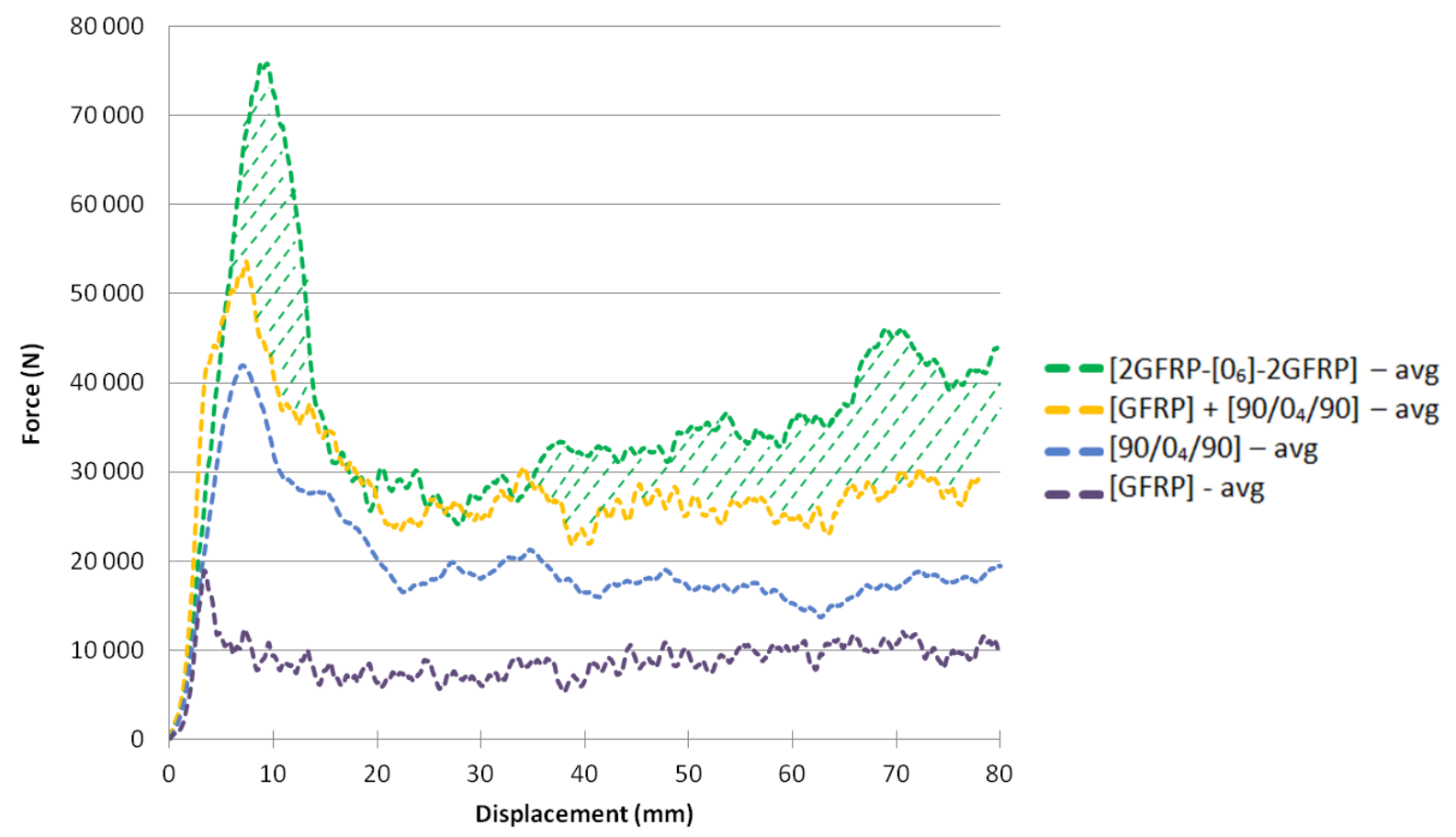

370 The dynamic coupling allowed gains of $20 \%$ and $22 \%$ on the absorbed energy and the SEA,

371 respectively (Tab. 7). The gain of the coupling in dynamics was slightly lower than that obtained in

372 statics: the [GFRP] tube showed a gain in SEA of $20.2 \mathrm{~J} / \mathrm{g}$ between the static and the dynamic tests,

373 resulting in an energy difference of $330 \mathrm{~J}$.

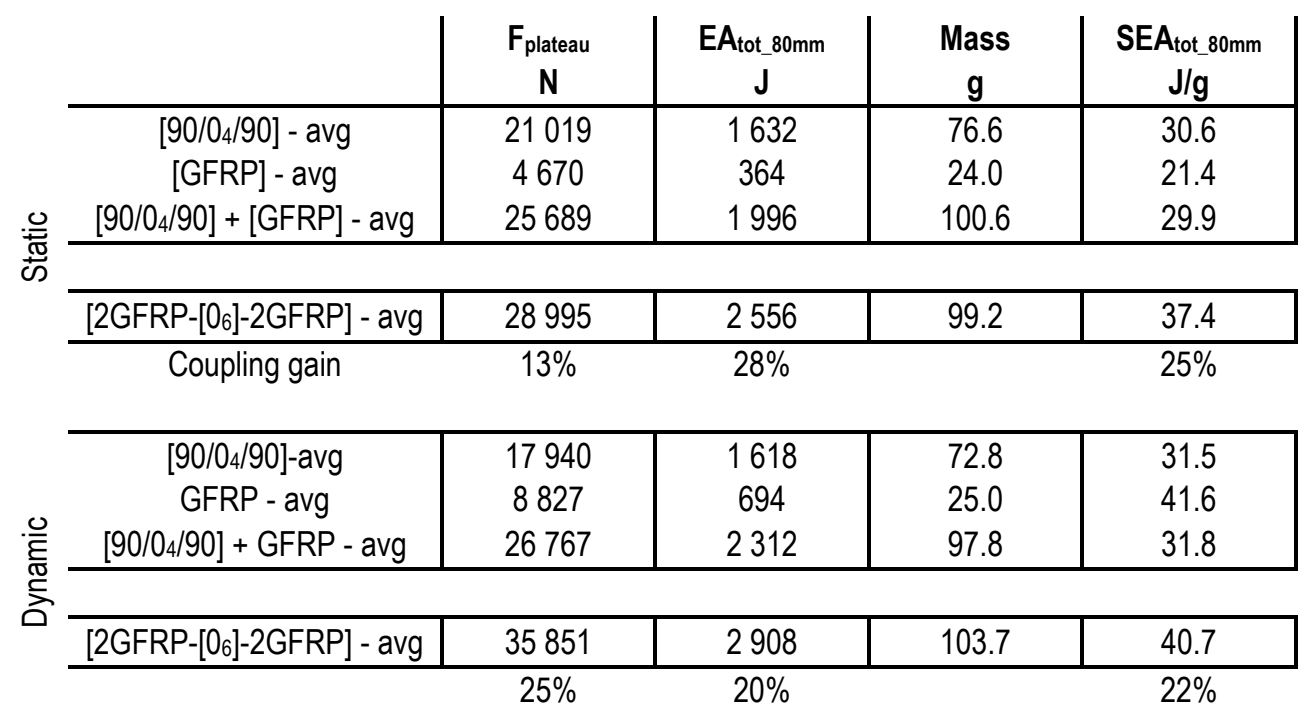


377 Fig. 29 shows a superposition of the dynamic curves of the glass and carbon fibre sandwich tubes.
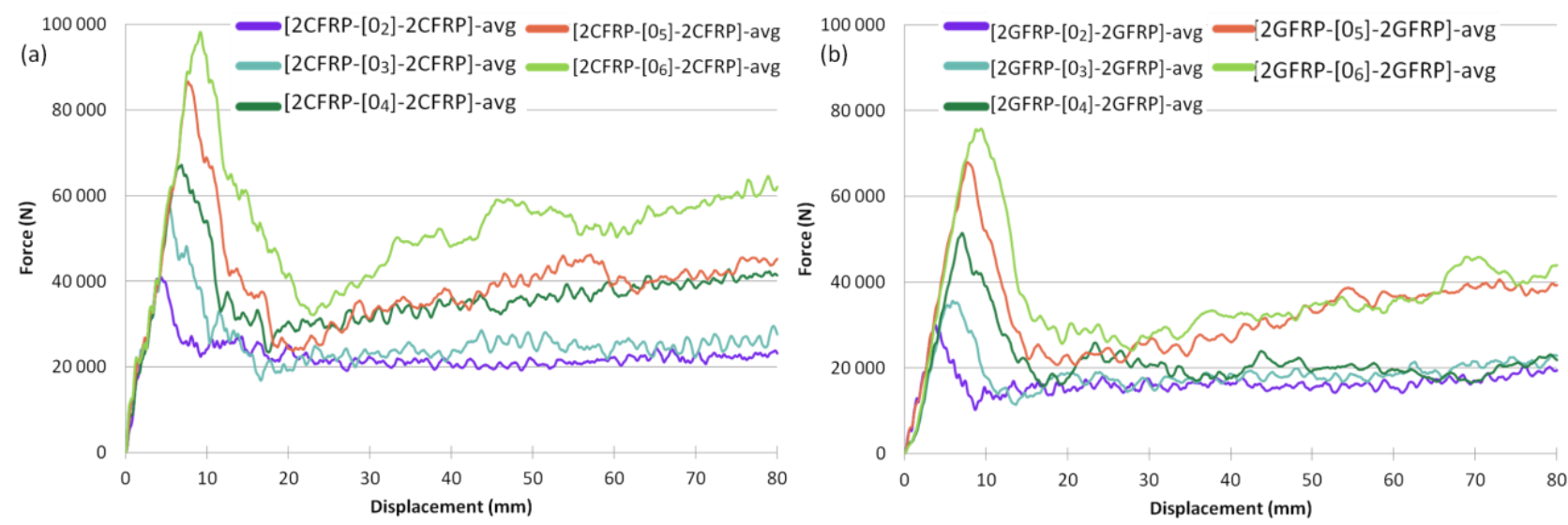

Fig. 29: Comparison of dynamic crushing of (a) CFRP and (b) GFRP skins.

The peak load on tubes with carbon fibre skins is higher than for those made of glass fibres. Average stress levels on carbon fibres are higher than those obtained with glass fibres. The energies absorbed and the SEA according to the types of skin and the number of 1214 layers are compared in Fig. 30.
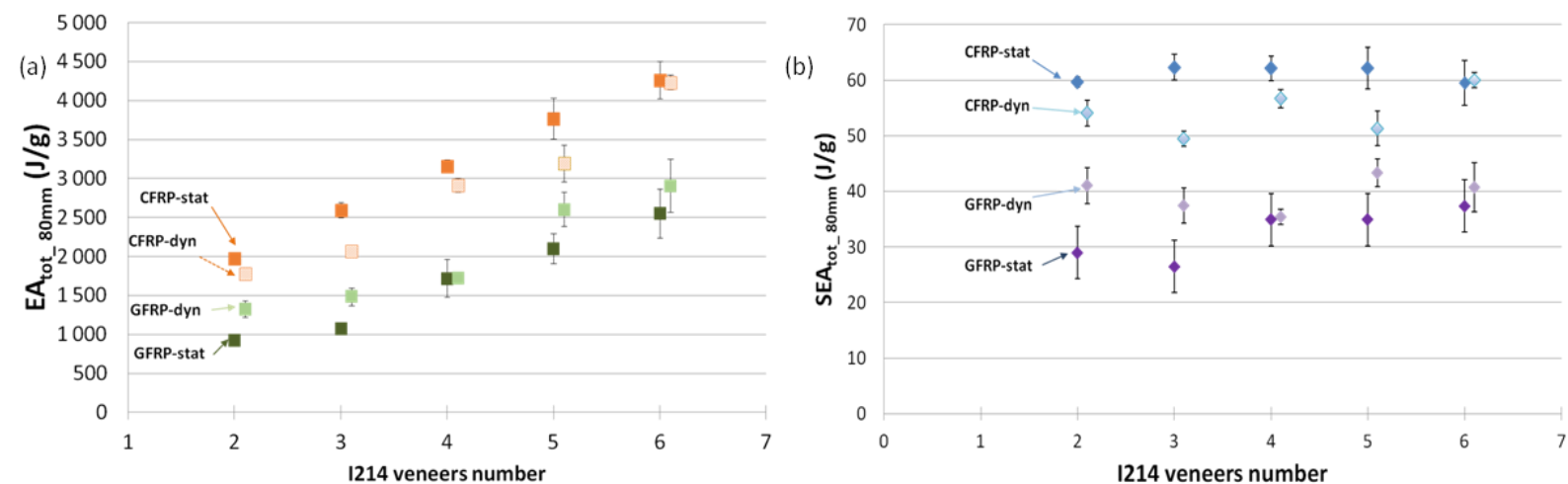

Fig. 30: Evolution of (a) $E A_{\text {tot_80mm }}$ (b) $S E A_{\text {tot_80mm }}$ according to the number of poplar layers, the nature of the skins, and static and dynamic conditions.

The energy absorbed, whether with carbon fibre or glass fibre skins, has an almost linear relationship with the number of 1214 poplar veneers. The linear increase in absorbed energy does not lead to an increase in SEA, which can be considered almost constant. In static and for carbon fibre skins, the SEA oscillates around a value of $61.2 \mathrm{~J} / \mathrm{g}$ and, in dynamics, around an average value of $54.3 \mathrm{~J} / \mathrm{g}$. With the fibreglass skins, in static mode and with the passage from 3 to 4 plies, a slight increase in the SEA is to be noted before it stagnates at a value of $35.7 \mathrm{~J} / \mathrm{g}$. Dynamically, glass fibre skins exhibit a more regular 


\section{Conclusions and perspectives}

Dynamic crushing tests of sandwich tubes with carbon fibre or glass - epoxy resin skins and poplar veneer core were investigated experimentally in this study. The tests showed that:

- The dynamic crushing of sandwich tubes with carbon skins $[2 \mathrm{CFRP}-[0 N]-2 \mathrm{CFRP}]_{2 \leq N \leq 6}$ gave interesting energy absorption results: an average dynamic SEA of $54.3 \mathrm{~J} / \mathrm{g}$. As the energy absorbed evolved linearly with the number of I214 layers employed, the dynamic SEA oscillated between 49.4 and $60 \mathrm{~J} / \mathrm{g}$. The monolithic CFRP tube had an SEA of $81.3 \mathrm{~J} / \mathrm{g}$ versus a maximum of $60 \mathrm{~J} / \mathrm{g}$ but the plateau force was $52,459 \mathrm{~N}$ for the sandwiches and 19,249 $\mathrm{N}$ for the CFRP tubes alone. An increase in the initial pseudo-linear slope between statics and dynamics was also observed. This can be attributed either to the carbon or to the wood or to the coupling of the two, since these two materials also showed an increase in apparent modulus in dynamics. The predominant failure mode in statics and dynamics was splaying. In dynamics, the internal confinement of debris was more pronounced than in statics. The combined use of poplar and carbon fibres allowed a gain on the SEA of the order of $40 \%$ in dynamics compared to the sum of the two materials crushed independently.

- The dynamic crushing of sandwich tubes with glass skins $[2 \mathrm{GFRP}-[0 \mathrm{~N}]-2 \mathrm{GFRP}]_{2 \leq \mathrm{N} \leq 6}$ also showed interesting energy absorption results. An average SEA of $39.3 \mathrm{~J} / \mathrm{g}$ was obtained in dynamic tests. The static and dynamic failure patterns of these tubes showed the formation of petals induced by splaying. The internal containment of debris was more marked in dynamics than in statics. The crushing of a monolithic glass fibre tube (of the same thickness as the skins) showed a strong improvement in its dynamic energy absorption properties: its unstable crushing in static generated large pieces of debris whereas the creation of fewer large and more microscopic pieces in dynamic led to more dissipative properties, raising the SEA from $21.4 \mathrm{~J} /$ 
interesting coupling of the two materials, with a gain of $20 \%$ of energy absorbed and $22 \%$ on SEA. In the same way as with carbon fibre skins, the transition from static to dynamic produced a greater load peak and a pseudo-linear slope.

423 Globally, the dynamic behaviour of these sandwiches with a poplar core confirms the results obtained in statics and the significant contribution in terms of energy absorbed by the wood core. Indeed, when the number of poplar layers of the core increase from two to six, the absorbed energy is doubled. The SEA obtained for the configurations studied is comparable to those of other materials (Fig. 33) but minimizes the use of composites in favour of wood. Because poplar is a wood species with a relatively low density, and thus with some of the lowest intrinsic mechanical characteristics, work on various wood species is envisaged in order to study their crash aptitudes and compare their behaviour and performance with 430 those of poplar 1214.

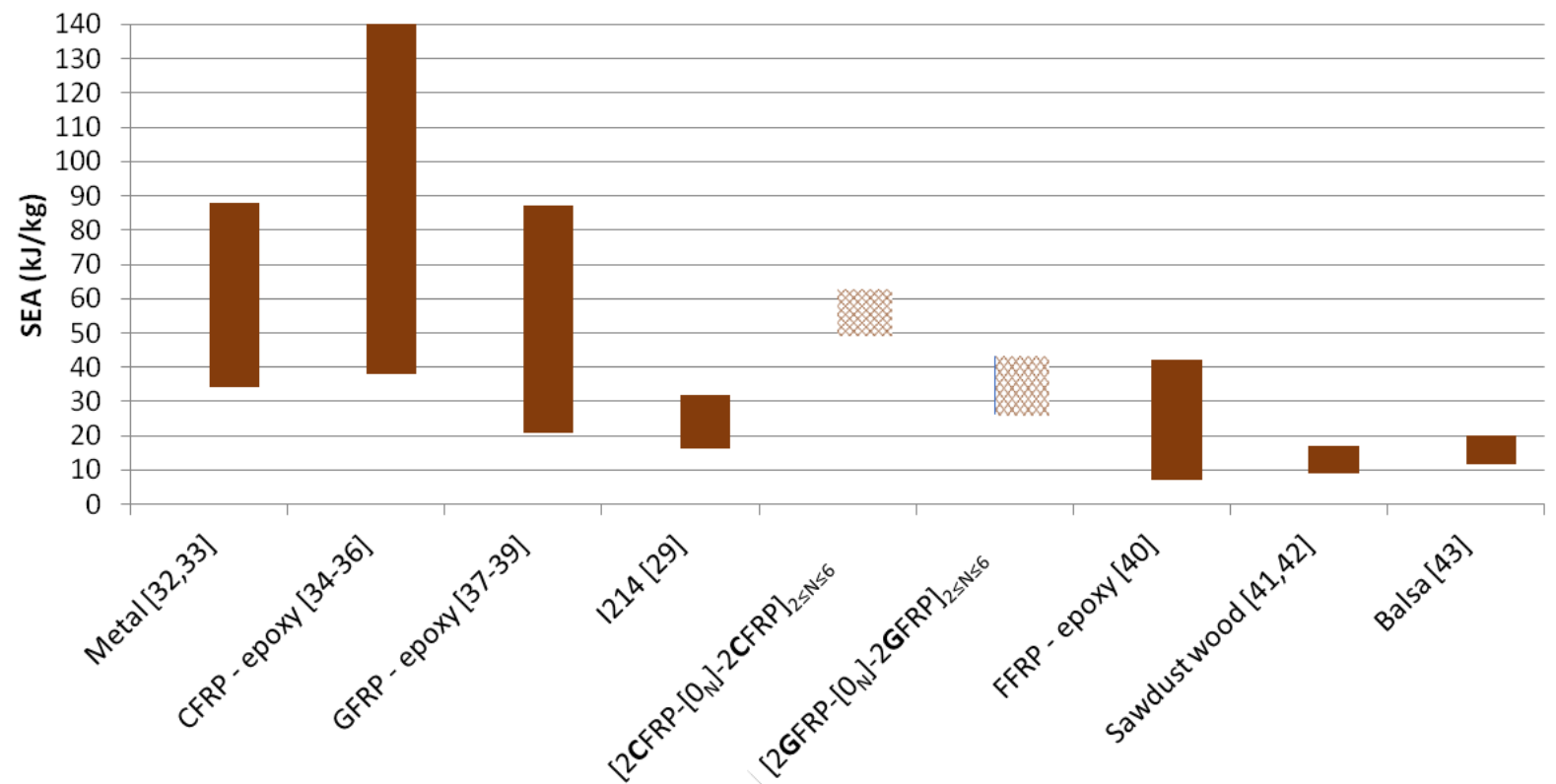

Fig. 23: SEA from of some materials ([29], [30]).

\section{Acknowledgements}

435 The authors thank the French Government for providing financial support (MESRI) and the Garnica company for providing 1214 veneers for this study.

\section{References}


[1] Forest Product Laboratory. Wood Handbook Wood as an Engineering Material. United States Department of Agriculture, Forest Service; 2010.

[2] R. Bergman, M. Puettmann, A. Taylor, and K.E. Skog, "The Carbon Impacts of Wood Products," For. Prod. J. vol. 64, pp 220-31, 2014. https://doi.org/10.13073/FPJ-D-14-00047.

[3] R. Asada, G. Cardellini, C. Mair-Bauernfeind, J. Wenger, V. Haas, D. Holzer, et al., "Effective bioeconomy? A MRIO-based socioeconomic and environmental impact assessment of generic sectoral innovations," Technol. Forecast. Soc. Change. Vol 153, n¹19946, 2020;153:https://doi.org/10.1016/j.techfore.2020.119946.

[4] B. Castanie, C. Bouvet, M. Ginot, "Review of composite sandwich structure in aeronautic applications," Comp. Part. C Open Access, Vol. 1, $\mathrm{n}^{\circ}$ 100004, 2020. https://doi.org/10.1016/j.jcomc.2020.100004.

[5] https://www.robin-aircraft.com// accessed 2021/07/09

[6] https://www.avionsmauboussin.fr/ accessed 2021/07/09

[7] https://aura-aero.com/ accessed 2021/07/09

[8] D. Kohl, P. Link and S. Böhm, "Wood as a Technical Material for Structural Vehicle Components," Procedia CIRP, Vol. 40, pp 557-61, 2016. https://doi.org/10.1016/j.procir.2016.01.133.

[9] Consortium WoodC.A.R. https://www.woodcar.eu/index.html. accessed 2021/07/09

[10] J. Susainathan, F. Eyma, E. De Luycker, A. Cantarel and B. Castanie, "Manufacturing and quasistatic bending behavior of wood-based sandwich structures," Comp. Struct., Vol. 182, pp 487-504, 2017. https://doi.org/10.1016/j.compstruct.2017.09.034.

[11] J. Smardzewski and K.W. Wojciechowski, "Response of wood-based sandwich beams with threedimensional lattice core," Comp. Struct., Vol. 2016, pp 340-49, 2019. https://doi.org/10.1016/j.compstruct.2019.03.009.

[12] S.W. Kavermann and D. Bhattacharyya, "Experimental investigation of the static behaviour of a corrugated plywood sandwich core," Comp. Struct. Vol. 207, pp 836-44, 2019. https://doi.org/10.1016/j.compstruct.2018.09.094.

[13] J. Liu , T. Zhang, W. Jiang Wand J. Liu, "Mechanical response of a novel composite Y-frame core sandwich panel under shear loading" Comp. Struct., Vol. 224, n 111064, 2019. https://doi.org/10.1016/j.compstruct.2019.111064.

[14] J. Smardzewski, "Experimental and numerical analysis of wooden sandwich panels with an auxetic core and oval cells," Mat. Des., Vol. 183, $n^{\circ}$ 108159, 2019. https://doi.org/10.1016/j.matdes.2019.108159.

[15] X. Wang, X. Shi, Q. Meng, Y. Hu and L. Wang, "Bending behaviors of three grid sandwich structures with wood facing and jute fabrics/epoxy composites cores," Comp. Struct., Vol. 252, n¹12666, 2020. https://doi.org/10.1016/j.compstruct.2020.112666. 
[16] F. Neveu, B. Castanié and P. Olivier, "The GAP methodology: a new way to design composite structures," Materials \& Design, Vol. 172, $n^{\circ} \quad 107755,2019$. https://doi.org/10.1016/j.matdes.2019.107755

491

492

493

494

495

496

497

498

499

500

501

502

503

504

505

506

507

508

509

510

511

512

513

514

515

516

517

518

519

520

521

522

523

524

525

526

527

528

529

530

531

532

533

534

535

536

[17] C. Atas and C. Sevim, "On the impact response of sandwich composites with cores of balsa wood and PVC foam," Comp. Struct., Vol.93, pp 40-48, 2010. https://doi.org/10.1016/j.compstruct.2010.06.018.

[18] J. Susainathan, F. Eyma, E. De Luycker, A. Cantarel and B Castanié," Experimental investigation of impact behavior of wood-based sandwich structures," Comp. Part A, Appl. Sci. Manuf., Vol. 109, pp 10-19, 2018. . https://doi.org/10.1016/j.compositesa.2018.02.029.

[19] J. Susainathan, F. Eyma, E. De Luycker, A. Cantarel and B Castanié," Numerical modeling of impact on wood-based sandwich structures", Mech. Adv. Mat. Struct., Vol. 27, pp 1583-98, 2020. https://doi.org/10.1080/15376494.2018.1519619.

[20] T.K. Demircioğlu, F. Balıkoğlu, O. İnal, N. Arslan, I. Ay and A. Ataş, "Experimental investigation on low-velocity impact response of wood skinned sandwich composites with different core configurations," Mat. Today. Com., Vol. 17, pp 31-9, 2018. https://doi.org/10.1016/j.mtcomm.2018.08.003.

[21] J. Smardzewski, Wooden sandwich panels with prismatic core - Energy absorbing capabilities. Comp. Struct., Vol. 230, nº 111535, 2019. https://doi.org/10.1016/j.compstruct.2019.111535.

[22] G. Palomba, G. Epasto and V. Crupi, "Lightweight sandwich structures for marine applications: a review", Mechanics of Advanced Materials and Structures, on line, https://doi.org/10.1080/15376494.2021.1941448

[23] W. Johnson, "Historical and present-day references concerning impact on wood," Int. J. Impact. Eng., Vol. 4, pp 161-74, 1986. https://doi.org/10.1016/0734-743X(86)90003-5.

[24] J. Susainathan, F. Eyma, E. De Luycker, A. Cantarel, C. Bouvet and B Castanié, "Experimental investigation of compression and compression after impact of wood-based sandwich structures", Comp. Struct., Vol. 220, pp 236-49, 2019. https://doi.org/10.1016/j.compstruct.2019.03.095.

[25] B. Castanié, J. J. Barrau, J. P. Jaouen, and S. Rivallant, "Combined shear/compression structural testing of asymmetric sandwich structures," Exp. Mech., vol. 44, no. 5, pp. 461-472, 2004. DOI:10.1007/BF02427957.

[26] F. Balıkoğlu T.K. Demircioğlu, O. İnal, N. Arslan and A. Ataş, "Compression after low velocity impact tests of marine sandwich composites: Effect of intermediate wooden layers," Comp. Struct., Vol. 183, pp 636-42, 2018. https://doi.org/10.1016/j.compstruct.2017.08.003.

[27] M. Neumann. Investigation of the Behaviour of Shock-Absorbing Structural Parts of Transport Casks Holding Radioactive Substances in Terms of Design Testing and Risk Analysis. Bergische Universität Wuppertal, 2009.

[28] N. Butler, "Computer modelling of wood-filled impact limiters" Nucl. Eng. Des., Vol. 150, pp 41724,1994. https://doi.org/10.1016/0029-5493(94)90161-9. 
[29] R. Guélou, F. Eyma, A. Cantarel, S. Rivallant, B. Castanié, "Crashworthiness of poplar wood Int. J. Impact. Eng., Vol. 147, $\mathrm{n}^{\circ}$ 103738, 2021. https://doi.org/10.1016/i.jijmpeng.2020.103738.

541 [30] R. Guélou, F. Eyma, A. Cantarel, S. Rivallant, B. Castanié, "Static crushing of wood based 542 sandwich composite tubes," Comp. Struct., Vol. 273, n 114317, 2021. 543 https://doi.org/10.1016/i.compstruct.2021.114317.

[31] D. Guillon, «Etude des mécanismes d'absorption d'énergie lors de l'écrasement progressif de structures composites à base de fibre de carbone », PhD Thesis. Institut Supérieur de l'Aéronautique et de l'Espace, ISAE, Ecole doctorale : Mécanique, énergétique, génie civil et procédés, 2008. 